\title{
Proteogenomics of adenosine-to-inosine RNA editing in the fruit fly
}

Ksenia G. Kuznetsova ${ }^{1 *}$, Anna A. Kliuchnikova ${ }^{1,2}$, Irina I. Ilina ${ }^{1}$, Alexey L.

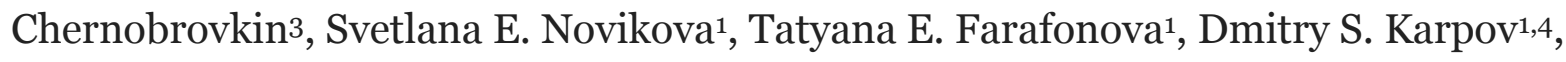
Mark V. Ivanov5,6, Anton O. Goncharov¹,2, Ekaterina V. Ilgisonis ${ }^{1}$, Olga E. Voronko, Shamsudin S. Nasaev², Victor G. Zgoda¹, Roman A. Zubarev3, Mikhail V. Gorshkov5,6, Sergei A. Moshkovskii ${ }^{1,2 *}$

${ }^{1}$ Institute of Biomedical Chemistry, Moscow, Russia

2Pirogov Russian National Research Medical University (RNRMU), Moscow,

Russia

3Karolinska Institutet, Stockholm, Sweden

4Engelhardt Institute of Molecular Biology, Russian Academy of Sciences, Moscow,

Russia

5Institute of Energy Problems of Chemical Physics, Russian Academy of Sciences, Moscow, Russia

${ }^{6}$ Moscow Institute of Physics and Technology (State University), Dolgoprudny, Moscow Region, Russia

*Corresponding authors: smosh@mail.ru; kuznetsova.ks@gmail.com

Running title: Proteogenomics of A-to-I RNA editing in fruit fly

\begin{abstract}
Adenosine-to-inosine RNA editing is one of the most common types of RNA editing, a posttranscriptional modification made by special enzymes. We present a proteomic study on this phenomenon for Drosophila melanogaster. Three proteome
\end{abstract}


data sets were used in the study: two taken from public repository and the third one obtained here. A customized protein sequence database was generated using results of genome-wide adenosine-to-inosine RNA studies and applied for identifying the edited proteins. The total number of 68 edited peptides belonging to 59 proteins was identified in all data sets. Eight of them being shared between the whole insect, head and brain proteomes. Seven edited sites belonging to synaptic vesicle and membrane trafficking proteins were selected for validation by orthogonal analysis by Multiple Reaction Monitoring. Five editing events in cpx, Syx1A, Cadps, CG4587 and EndoA were validated in fruit fly brain tissue at the proteome level using isotopically labeled standards. Ratios of unedited-to-edited proteoforms varied from 35:1 (Syx1A) to 1:2 (EndoA). Lys-137 to Glu editing of endophilin A may have functional consequences for its interaction to membrane. The work demonstrates the feasibility to identify the RNA editing event at the proteome level using shotgun proteomics and customized edited protein database.

\section{Keywords}

Proteogenomics, RNA editing, RNA-dependent adenosine deaminase, ADAR, shotgun proteomics, multiple reaction monitoring, SNARE complex, endophilin A. 


\section{Introduction}

RNA editing is a type of posttranscriptional modification made by specific enzymes. Being first described to happen in mitochondrial RNAs of kinetoplastid protozoa ${ }^{1}$, it was then observed for various organisms and different kinds of RNA ${ }^{2}$. RNA editing includes nucleotide insertion or deletion, as well as deamination of cytosine and adenosine bases. Cytosine gets transformed into uridine by cytidine deaminase (CDA) 3, and adenosine is converted to inosine by adenosine deaminases acting on RNA (ADARs) 4,5. While the former is described mostly for plant cells 6,7 , although it occurs also during apolipoprotein B synthesis 3, the latter is common for neural and glandular tissues of many invertebrate and vertebrate species ${ }^{8}$.

Messenger RNA editing is the most interesting kind of RNA editing for proteomics as it may affect the primary structure of proteins. At the same time, specifically adenosine to inosine (A-to-I) editing provides the interest to neurobiology, because, reportedly, this type of modification is believed to have a function of rapid fine neuron tuning 9. Protein products of RNA editing can exist in organisms in both variants. The ratio of these proteoforms may possess a functional significance ${ }^{10,11}$.

To date, the phenomenon of RNA editing was studied mostly at the transcriptome level that included a number of works on Drosophila melanogaster ${ }^{12}$. Yet, a workflow for identification and characterization of the RNA editing products have not been fully developed. The first study on the RNA editing at the proteome level was focused on characterization of all types of proteoforms for the rat liver ${ }^{13}$. However, liver is not 
reported as a tissue of functional A-to-I RNA editing ${ }^{14}$, and twenty events of RNA editing identified for rat proteome were simply listed without further discussion 13 .

After publishing the first version of the current work as a preprint, two more papers were represented that studied ADAR-mediated editing events at the level of proteome. First of them disclosed a lot of RNA editing sites in an octopus 15 and stated that this animal widely used RNA editing to tune its cellular functions in various environmental conditions. Flexibility of the cephalopod editome in comparison with mammalian species, at the same time, provided its genome conservation. In this work, which was mainly focused on RNA analysis, a survey of proteome also was done to identify hundreds editing sites. However, the authors did not use group-specific filtering of the results and those latter were not validated by orthogonal methods.

More recent paper has extracted proteins changed by RNA editing in human cancer tissues from proteogenomic big data of TCGA cancer project ${ }^{16}$. In total, 13 editing sites were deduced and properly validated in proteomes from TCGA data. At least one of those sites, in Copa vesicle transport protein, was suspected to be involved in breast cancer progression ${ }^{16}$.

With the introduction of proteogenomic approach as use of customized nucleic acid databases for specific samples ${ }^{17}$, the workflow for proteomic investigation of the products of RNA editing became pretty clear. First, a customized proteomic database is made, based on known editome of the organism under study ${ }^{18}$. As the editome includes extra variants of the edited mRNA sequences, this database contains both unedited and edited peptide variants. Then, the shotgun proteomic spectra are searched against this database. Finally, information about the edited peptides is extracted from the search results and optionally validated to exclude false discoveries ${ }^{19}$. 
A-to-I RNA editing at the transcriptome level has been studied comprehensively for D. melanogaster by Hoopengardner et al. using comparative genomic approaches ${ }^{20}$. In the other study by Rodriguez et al. authors used nascent RNA sequencing ${ }^{21}$. Comparing wild type and the adar mutant flies they have shown the critical role the ADAR is playing in RNA editing. A method of cDNA to genomic DNA comparison was used to find RNA editing sites by Stapleton et al. ${ }^{22}$.

More recently, a genome-wide analysis of A-to-I RNA editing sites was performed and an editome of Drosophila was thoroughly characterized ${ }^{23}$. The analysis revealed 3581 high-confidence editing sites in the whole body of a fruit fly. The authors used a single-molecule sequencing method with the introduction of the so-called 'three-letter' alignment procedure to avoid misreading of the A-to-G substitution sites for wild type and adar-deficient flies. This allowed increasing the accuracy of the database containing the A-to-I RNA editing sites and provided the most complete editome of $D$. melanogaster. This editome was further used for generating the customized protein database in this work. The summary of the results of previous efforts to study the $D$. melanogaster editome and the evolutional analysis of the function of A-to-I editing in seven Drosophila species was also provided last year by $\mathrm{Yu}$ et al. ${ }^{24}$.

It also has been shown that A-to-I editing happens as a response to environmental changes such as temperature ${ }^{12}$, which makes great sense in terms of the purpose of editing versus genomic recoding evolutionally. The authors have described 54 A-to-I editing sites, some of which are demonstrating significant differences in edited-tounedited transcript ratios in the flies raised at 10,20 , and $30^{\circ} \mathrm{C}$. The list of sites consists of various genes including adar itself. 
From previous works with successful use of customized databases to identify protein-coding genome variants ${ }^{25}$, we deduced that similar customized databases may be designed protein coding RNA editome. In this study, as a model animal we used a fruit fly with well characterized A-to-I RNA editome ${ }^{23}$. The aim of the study was identifying the RNA editing events in the proteome followed by validation of selected edited peptides by targeted mass spectrometry. To our knowledge, this is a first attempt to characterize RNA editing in Drosophila at the proteome level. Tandem mass spectrometry data were taken from recent shotgun proteomics studies ${ }^{26,27}$ available at ProteomeXchange (http://www.proteomexchange.org/) ${ }^{28}$. These results contain data for proteome of Drosophila's whole bodies ${ }^{26}$ and whole heads ${ }^{27}$. The other data set for Drosophila's brain proteome was obtained here using high-resolution mass spectrometry.

\section{Experimental section}

\section{Experimental design}

The shotgun proteomic analysis was performed using 1 sample consisted of 200 isolated fruit fly brains combined. The number of technical replicates in the shotgun experiment was 3. For the targeted proteomic experiment 2 samples had been prepared. The first one was used for preliminary MRM experiment and had been derived from flies of different age. Two RNA editing sites were validated in this experiment: cpx and Syx1A. During each MRM experiment 5 technical replicates have been done. The details of each experiment are provided below. The second MRM experiment was performed on the sample consisting of 80 brains of 72 hours old male flies. The sites validated in the 
second MRM experiment are cpx, Syx1A, CG4587, Atx2, Cadps, RhoGAP1ooF, and EndoA. A sample consisting of 100 fly heads was used for the genomic sequencing experiment and another 100 head sample was utilized for RNA study. The summarizing table of all the Drosophila samples used in this work is provided in Table S-1.

The data from 3 proteomes were used for the RNA editing sites search. One proteome was obtained experimentally here and the other two were taken from Xing et al. ${ }^{26}$ and Aradska et al. ${ }^{27}$. A thorough schematic explanation of the whole workflow performed is given in Fig. 1.

During the shotgun data analysis, the peptide identification was held at a $1 \%$ false discovery rate as described in details in the corresponding section.

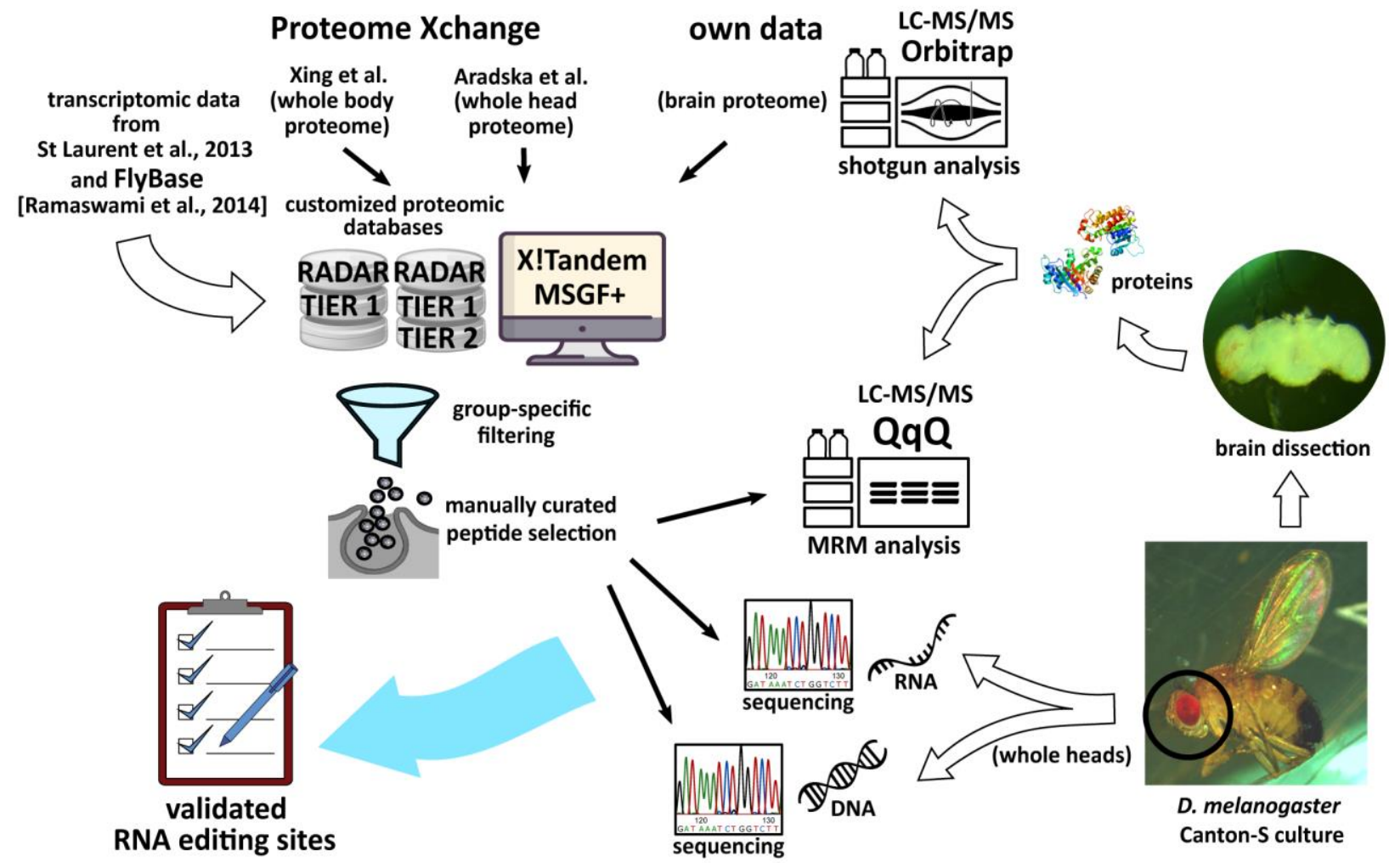


Figure 1. The workflow of this study. Fly brains were extracted and subjected to trypsin digestion following LC-MS/MS analysis. The heads were used for DNA and RNA extraction with the following genomic and transcriptomic sequencing. Two more datasets were taken from Proteome exchange from Xing et al. ${ }^{26}$, and Aradska et al. ${ }^{27}$ Two customized databases were generated and all three proteomic datasets were searched against them with two search engines. The transcriptomic data were taken from St Laurent et al. 23 and RADAR 29 . Finally, a list of validated RNA editing sites was generated.

\section{Drosophila melanogaster culture}

Live samples of Drosophila melanogaster Canton S line were kindly provided by Dr. Natalia Romanova from Moscow State University, Department of Biology. The flies were kept on Formula 5-24 instant Drosophila medium (Carolina Biological Supply Company, USA) in $50 \mathrm{ml}$ disposable plastic test tubes. The initial temperature for the fly culture was $25^{\circ} \mathrm{C}$. The flies had been transferred to a new tube as they reached the adult stage. For general samples that were used for shotgun proteome analysis, as well as for the initial targeted analysis. Two hundred flies were selected from the culture regardless of their age. For the second MRM experiment 80 male flies were used, 72 hours old.

\section{Brain dissection}

Frozen flies were kept on ice in a Petri dish during the whole procedure. Each fly was taken out, and the body was rapidly removed by a needle. The head was placed into 0.01 M PBS at pH 7.4 (recovered from tablets, Sigma-Aldrich, USA), and the head 
capsule was torn apart by two forceps under visual control through a stereo microscope (Nikon SMZ645, Japan) with 10x1 magnification. The extracted brains were collected into the same PBS, and then centrifuged at $6000 \mathrm{~g}$ for 15 minutes (Centrifuge 5415R, Eppendorf, Germany). The buffer solution was removed and the brain pellet was frozen at $-80^{\circ} \mathrm{C}$ for the future sample preparation. The photo of the dissected brain was taken with DCM510 Microscope CMOS Camera (Scope Tek, China).

\section{Protein extraction, trypsin digestion, total protein and peptide} concentration measurement

Brain pellet containing 200 brains was resuspended in $100 \mu \mathrm{L}$ lysis solution containing $0.1 \%(\mathrm{w} / \mathrm{v}$ ) Protease MAX Surfactant (Promega. USA), $50 \mathrm{mM}$ ammonium bicarbonate, and 10\% (v/v) acetonitrile (ACN). The cell lysate was stirred for $60 \mathrm{~min}$ at $550 \mathrm{rpm}$ at room temperature. The mixture was then subjected to sonication by Bandelin Sonopuls HD2070 ultrasonic homogenizer (Bandelin Electronic, Germany) at $30 \%$ amplitude using short pulses for $5 \mathrm{~min}$. The supernatant was collected after centrifugation at $15.700 \mathrm{~g}$ for $10 \mathrm{~min}$ at $20^{\circ} \mathrm{C}$ (Centrifuge $5415 \mathrm{R}$, Eppendorf, Germany). Total protein concentration was measured using bicinchoninic acid assay (BCA Kit, Sigma-Aldrich, USA).

Two $\mu \mathrm{L}$ of $500 \mathrm{mM}$ dithiothreitol (DTT) in $50 \mathrm{mM}$ triethylammonium bicarbonate (TEABC) buffer were added to the samples to the final DTT concentration of $10 \mathrm{mM}$ followed by incubation for $20 \mathrm{~min}$ at $56^{\circ} \mathrm{C}$. Thereafter, $2 \mu \mathrm{L}$ of $500 \mathrm{mM}$ iodoacetamide (IAM) in $50 \mathrm{mM}$ TEABC were added to the sample to the final IAM concentration of 10 $\mathrm{mM}$. The mixture was incubated in the darkness at room temperature for $30 \mathrm{~min}$. 
The total resultant protein content was digested with trypsin (Trypsin Gold, Promega, USA). The enzyme was added at the ratio of 1:40 (w/w) to the total protein content and the mixture was incubated overnight at $37^{\circ} \mathrm{C}$. Enzymatic digestion was terminated by addition of acetic acid ( $5 \% \mathrm{w} / \mathrm{v})$.

After the reaction was stopped, the sample was stirred (500 rpm) for $30 \mathrm{~min}$ at $45^{\circ} \mathrm{C}$ followed by centrifugation at $15,700 \mathrm{~g}$ for $10 \mathrm{~min}$ at $20^{\circ} \mathrm{C}$. The supernatant was then added to the filter unit (10 kDa, Millipore, USA) and centrifuged at 13,40og for 20 min at $20^{\circ} \mathrm{C}$. After that, $100 \mu \mathrm{L}$ of $50 \%$ formic acid were added to the filter unit and the sample was centrifuged at $13,400 \mathrm{~g}$ for $20 \mathrm{~min}$ at $20^{\circ} \mathrm{C}$. The final peptide concentration was measured using Peptide Assay (Thermo Fisher Scientific, USA) on a NanoDrop spectrophotometer (Thermo Fisher Scientific, USA). Sample was dried up using a vacuum concentrator (Eppendorf, Germany) at $45^{\circ} \mathrm{C}$. Dried peptides were stored at $80^{\circ} \mathrm{C}$ until the LC-MS/MS analysis.

\section{Shotgun proteomic analysis}

Chromatographic separation of peptides was achieved using homemade C18 column, $25 \mathrm{~cm}$ (Silica Tip 360 $\mu \mathrm{m}$ OD, $75 \mu \mathrm{m}$ ID, New Objective, USA) connected to an UltimateTM 3000 RSLC nano chromatography system (Thermo Fisher Scientific. USA). Peptides were eluted at $300 \mathrm{~nL} / \mathrm{min}$ flow rate for $240 \mathrm{~min}$ at a linear gradient from $2 \%$ to $26 \% \mathrm{ACN}$ in $0.1 \%$ formic acid. Eluted peptides were ionized with electrospray ionization and analyzed on Orbitrap QExactive Plus mass spectrometer (Thermo Fisher Scientific, USA). The survey MS spectrum was acquired at the resolution of 60,000 in the range of $\mathrm{m} / \mathrm{z}$ 200-2000. 
MS/MS data for 20 most intense precursor ions, having charge state of 2 and higher, were obtained using higher-energy collisional dissociation (HCD) at a resolution of 15,000 . Dynamic exclusion of up to 500 precursors for 60 seconds was used to avoid repeated analysis of the same peptides.

Proteomic data obtained in this work were deposited in the public repository ProteomeXchange (http://www.proteomexchange.org/) ${ }^{28}$ under the accession number PXDo09590 .

\section{Customized database generation}

Fly genomic coordinates of RNA editing sites mapped to exons were obtained from RADAR (1328 sites) 29 and genome-wide studies performed by St Laurent et al. 23. We used two lists of RNA editing sites from previous works ${ }^{23}$. The first one, named TIER1 contained 645 exonic non-synonymous high-confident editing sites with high validation rate of $>70 \%$. The second list, named TIER2, contained 7986 less confident sites with expected validation rate of $9 \%$. Genomic coordinates obtained from these sources were converted to the coordinates of the recent Drosophila genome assembly Dm6 using FlyBase (http://flybase.org/) 30. Changes in protein sequences induced by RNA editing were annotated for all three lists (RADAR, TIER1, and TIER2) using Variant Annotation Integrator (VAI) (http://genome.ucsc.edu/cgi-bin/hgVai). The input was prepared using Python script developed in-house (Script S-2). The VAI output was used to create VAI protein databases containing original and edited fly proteins using another Python script (Script S-3). These protein databases were used to generate the edited protein databases for MSGF+ and X!Tandem searches using another in-house developed Python script (Script S-4). The databases were named RADAR, TIER1, and TIER2 and can be 
found in Supporting information under the names Database S-5, S-6 and S-7, respectively.

\section{MSGF+ and X!Tandem search parameters}

Peptide identification for all data sets was performed using MSGF+ version 2017.01.13 ${ }^{31}$ as well as with X!Tandem version 2012.10.01.1 ${ }^{32}$ against the three customized databases combined with the UniProt database for D. melanogaster downloaded in April 2017 and containing 42519 entries.

$\mathrm{X}$ !Tandem searches were performed using $10 \mathrm{ppm}$ and 0.01 Da mass tolerances set for precursor and fragment ions, respectively. For the datasets obtained using a linear ion trap and taken from Xing at al. ${ }^{26}$, and Aradska et al. ${ }^{27}$, the fragment mass tolerance was $0.3 \mathrm{Da}$. Up to 1 missed cleavage was allowed. The same parameters were used for the MSGF+ search, except the instrument-specific parameters that were set according to the instruments specified for the particular data set. Carbamidomethylation of cysteine was used as fixed modification. Methionine oxidation and the protein N-terminal acetylation were used as variable modifications. The false discovery rate (FDR) was set to $1 \%$. The group-specific FDR method, which provides separate FDR for the variant peptides as described elsewhere 25 , was employed. A target-decoy approach was used to calculate FDR according to the following equation 33: FDR = (number of variant decoy PSMs+1)/number of variant target PSMs. All the edited peptides have been filtered group-specifically according to the $1 \%$ FDR. The filtration was performed using a Python script with a specific Pyteomics library constructed for he proteomic data analysis 34 . Group-specific filtering was done separately for the peptides from RADAR, TIER 1 and TIER2 databases. 


\section{Open search}

For open search, X!Tandem was used with the same settings except precursor mass tolerance which was set at $500 \mathrm{Da}$. The peptide-spectrum matches (PSMs) including decoys were grouped by mass shifts with the accuracy of $0.01 \mathrm{Da}$ and filtered separately within each group. The open search was performed only on the data gained in our own experiment, since the other two data sets contain data with tandem spectra recorded in the linear ion trap with low resolution.

\section{Peptide standard synthesis}

Peptides were synthesised by solid phase method using amino acid derivatives with 9-fluorenyl methyloxy carbonyl (Fmoc) protected $\alpha$-amino groups (Novabiochem). The procedure was performed as described elsewhere35. Stable isotope-containing leucine (Fmoc-Leu-OH-13 $\mathrm{C}_{6},{ }_{15} \mathrm{~N}$, Cambridge Isotope Laboratories) was applied for labeling 11-plex peptides from $c p x$ protein (NQMETQVNE $\boldsymbol{L}^{\boldsymbol{h}} \mathrm{K}$ and NQIETQVNE $\boldsymbol{L}^{\boldsymbol{h}} \mathrm{K}$ ). A resin with attached stable isotope-labeled lysine (L-Lys (Boc) $\left({ }^{13} \mathrm{C}_{6}, 99 \% ;{ }^{15} \mathrm{~N}_{2}, 99 \%\right){ }_{2}-$ Cl-Trt, Cambridge Isotope Laboratories) was used for synthesis of peptides of SyxiA (IEYHVEHAMDYVQTATQDT $\boldsymbol{K}^{\boldsymbol{h}}$ and IEYHVEHAVDYVQTATQDTK $\boldsymbol{h}^{\boldsymbol{h}}$ ), EndoA

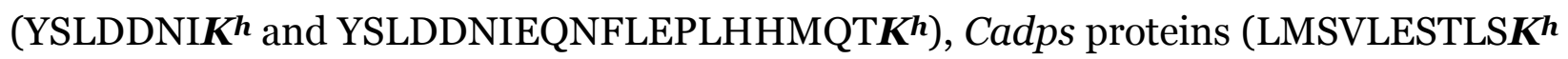
and LVSVLESTLSK $\boldsymbol{h}^{\boldsymbol{h}}$ ), and one of the peptides of Atx2 (GVGPAPSANASADSSSK $\boldsymbol{K}^{\boldsymbol{h}}$ ). Resin with attached stable isotope-labeled arginine (L-Arg (Pbf) $\left({ }^{13} \mathrm{C}_{6}, 99 \% ;{ }_{15} \mathrm{~N}_{4}, 99 \%\right)$ 2-Cl-Trt, Cambridge Isotope Laboratories) was used for synthesis of peptides of $C G 4587$ 
(LVTTVSTPVFD $\boldsymbol{R}^{\boldsymbol{h}}$ and LVTTVSTPVFDG $\boldsymbol{R}^{\boldsymbol{h}}$ ), RhoGAP1OoF (YLLQIWPQPQAQH $\boldsymbol{R}^{\boldsymbol{h}}$ and YLLQIWPQPQAQHQR $\boldsymbol{R}^{\boldsymbol{h}}$ ) and Atx2 (GVGPAPSANASADSSS $\boldsymbol{R}^{\boldsymbol{h}}$ ).

Further steps of synthesis were also preceded as described 35.

For synthesis quality control, a simple LC-MS analysis was held using a chromatographic Agilent ChemStation 1200 series connected to an Agilent 1100 series LC/MSD Trap XCT Ultra mass spectrometer (Agilent, USA). Since our peptides contained methionine residues, the quality control also included manual inspection of the MS and MS/MS spectra for possible presence of the peaks produced by oxidized compounds. No such peaks were found in our case.

Concentrations of synthesised peptides were determined using conventional amino acid analysis with their orthophtalic derivatives according to standard amino acid samples.

\section{Multiple Reaction Monitoring experiments}

Each sample was analyzed using Dionex UltiMate 3000 RSLC nano System Series (Thermo Fisher Scientific, USA) connected to a triple quadrupole mass spectrometer TSQ Vantage (Thermo Fisher Scientific, USA) in five technical replicates. Generally, $1 \mu \mathrm{l}$ of each sample containing $2 \mu \mathrm{g}$ of total native peptides and $100 \mathrm{fmol}$ of each standard peptide was loaded on a precolumn, Zorbax 30oSB-C18 $(5 \mu \mathrm{m}, 5 \times 0.3 \mathrm{~mm})$ (Agilent Technologies, USA) and washed with $5 \%$ acetonitrile for $5 \mathrm{~min}$ at a flow rate of 10 $\mu \mathrm{l} /$ min before separation on the analytical column. Peptides were separated using RPHPLC column, Zorbax 30oSB-C18 $(3.5 \mu \mathrm{m}, 150 \mathrm{~mm} \times 75 \mu \mathrm{m})$ (Agilent Technologies, USA) using a linear gradient from $95 \%$ solvent A (o.1\% formic acid) and $5 \%$ solvent B 
(80\% acetonitrile, $0.1 \%$ formic acid) to $60 \%$ solvent A and $40 \%$ solvent B over 25 minutes at a flow rate of $0.4 \mu \mathrm{l} /$ minute.

MRM analysis was performed using Triple quadrupole TSQ Vantage (Thermo Scientific, USA) equipped with a nano-electrospray ion source. A set of transitions used for the analysis is shown in Table S-8. Capillary voltage was set at $2100 \mathrm{~V}$, isolation window was set to $0.7 \mathrm{Da}$ for the first and the third quadrupole, and the cycle time was 3 s. Fragmentation of precursor ions was performed at 1.0 mTorr using collision energies calculated by Skyline 3.1 software (MacCoss Lab Software, USA) (https://skyline.ms/project/home/software/Skyline/begin.view) (Table S-8). Quantitative analysis of MRM data was also performed using Skyline 3.1 software. Quantification data were obtained from the "total ratio" numbers calculated by Skyline represented a weighted mean of the transition ratios, where the weight was the area of the internal standard. Five transitions were used for each peptide including the isotopically labeled standard peptide. Isotopically labeled peptide counterparts were added at the concentration of $1 \mathrm{mg} / \mathrm{ml}$. Each MRM experiment was repeated in 5 technical runs. The results were inspected using Skyline software to compare chromatographic profiles of endogenous peptide and stable-isotope labeled peptide. CV of transition intensity did not exceed $30 \%$ in technical runs.

All the MRM spectra can be downloaded from Passel (http://www.peptideatlas.org/passel/) ${ }^{36}$ under the accession number PASSo1175.

\section{Genomic sequencing}


DNA was extracted from 100 Drosophila heads (Table S-1, sample \#5) using the standard phenol-chloroform method described elsewhere 37 . The polymorphic sites of nine D. melanogaster genes (M244V in Syx1A, K398R in Atx2, Y390C in Atpalpha, R489G in CG4587, I125M in cpx, K137E in EndoA, Q170oR in AlphaSpec, M1234V in Cadps and Q1142R in RhoGAP1OoF) were genotyped using Sanger sequencing on Applied Biosystems 3500xL genetic analyzer and SeqScape $®$ software (Thermo Fisher Scientific, USA). Initial PCRs were performed in a $25 \mu \mathrm{L}$ volume containing $50 \mathrm{ng}$ genomic DNA template, 10x PCR buffer, 0.5 U of HS Taq DNA Polymerase, $0.2 \mathrm{mM}$ dNTPs (all from Evrogen, Russia), and 80 pmol of each primer. The PCR cycling conditions were the same for all SNPs and were as follows: $95^{\circ} \mathrm{C}$ for 5 minutes followed by 35 cycles of $94^{\circ} \mathrm{C}$ for 15 seconds, $59^{\circ} \mathrm{C}$ for 20 seconds, $72^{\circ} \mathrm{C}$ for 20 seconds and final elongation at $72^{\circ} \mathrm{C}$ for 6 minutes. Primers were designed using PerlPrimer free software (http://perlprimer.sourceforge.net/) and are shown in the Table S-9. The same primers were used for sequencing. PCR products were then cleaned up by incubation with the mix of $1 \mathrm{U}$ of ExoI and $1 \mathrm{U}$ of SAP (both enzymes from Thermo Fisher Scientific, USA) at $37^{\circ} \mathrm{C}$ for 30 minutes, followed by $80^{\circ} \mathrm{C}$ for 15 minutes. The sequencing reactions with following EDTA/ethanol purification were carried out using BigDye Terminator v3.1 Cycle Sequencing Kit (Thermo Fisher Scientific, USA) according to manufacturer's instructions.

\section{RNA sequencing with inosine chemical erasing}

In order to identify inosines on RNA strands, inosine chemical erasing (ICE) was used $3^{8}$ with minor modifications. Briefly, total RNA from 100 fly heads was extracted using an RNeasy mini kit (Qiagen. Germany). Then, $10 \mu \mathrm{g}$ of RNA was cyanoethylated 
(CE) by incubation in $38 \mu \mathrm{l}$ solution $(50 \%(\mathrm{v} / \mathrm{v})$ ethanol, $1.1 \mathrm{M}$ triethyl ammonium acetate, $\mathrm{pH}$ 8.6) with (CE+) or without (CE-) $1.6 \mathrm{M}$ acrylonitrile at $70^{\circ} \mathrm{C}$ for $30 \mathrm{~min}$. After cyanoethylation, RNA was purified using an RNeasy MinElute kit (Qiagen, Germany) and reverse transcribed using Low RNA Input Linear Amp Kit (Agilent Technologies, USA). Sites of nine D. melanogaster genes (Syx1A, Atx2, Atpalpha, CG4587, cpx, EndoA, Alpha-Spec, Cadps, RhoGAP1OoF) were analyzed by a Sanger sequencing described in the previous section. According to the known method ${ }^{38}$, the editing site in $\mathrm{CE}$ - state can be detected as combined signal from $\mathrm{A}$ and $\mathrm{G}$ in the sequence chromatogram. For $\mathrm{CE}+$ state, the signal can be detected as A. For those sites that are almost $100 \%$ edited, no amplification of the cDNA can be detected in the $\mathrm{CE}+$ state 38 .

\section{Results}

\section{Search for RNA editing sites in deep Drosophila proteome}

Tandem mass spectrometry data were taken from recent shotgun proteomics studies 26,27 available at ProteomeXchange. These results contain data for proteome of Drosophila's whole bodies ${ }^{26}$ and whole heads ${ }^{27}$. The other dataset for Drosophila's brain proteome was obtained here using high-resolution mass spectrometry. Note also that the proteome characterized by Aradska et al. ${ }^{27}$ contains only membrane proteins as they were intentionally extracted during the sample preparation. In total, three data sets, representing proteomes of the whole body, the head, and the brain of Drosophila were available for the analysis in this study. 
As noted above, the search for the RNA editing sites was performed using the proteogenomic approach 39. Following this approach, the standard fruit fly proteome FASTA database was extended with addition of the edited protein variants found from the transcriptomic data. Three FASTA files containing protein databases with edited sequences derived from transcriptome sequencing results 23 and FlyBase were generated as described in Method section and named TIER1, TIER2, and RADAR. These FASTA files were combined with the UniProt database for D. melanogaster (version form April of 2017,42519 entries) containing the unedited peptides of fruit fly and used for the searches. After that, group-specific filtering was done separately for the peptides from RADAR, TIER1 and TIER2 databases. Figure 1 shows schematically the workflow used in this work. The edited peptide identifications are listed in Table 1. The genomic coordinates, unedited sequences and UniProt IDs of the peptides are listed in Table S-1.

In all the data studied, 68 peptides corresponding to the RNA editing events were identified (Table 1). These peptides represent 59 proteins, since some of them, according to transcriptomic data, could contain several editing sites 23 . However, because a massspectrometry provides partial protein sequence coverage only, some of the editing events for a protein are missing in the shotgun proteomics data.

Among edited sites listed in Table 1, only 8 are identified in all datasets used in the study. This group, as expected, includes proteins with brain localization, because inhome data is produced from isolated brains. Other 25 sites are found in at least two of datasets. Finally, remainder of edited sites (35) are found only in one study.

\section{Open search for additional filtering of false-positives}


Open search was performed in order to assign some level of confidence to a particular amino acid substitution that is found to happen due to RNA editing, but may also be a false result introduced by an amino acid modification ${ }^{40}$. The results of the open search are presented in Table S-10 (columns AA, AB, AC). Each amino acid substitution has its "open search rank" which was calculated based on percentage of open search hits falling into corresponding mass shift interval. If this mass shift would be overrepresented, most likely, it corresponded to the chemical modification rather than to the real amino acid substitution. Thus, the open search rank indirectly and inversely represents the likelihood of its mass shift to be caused by a modification. Based on the open search approach, some peptides containing N-to-D and Q-to-E substitutions have been removed from the results because such substitution cannot be told from deamidation. The open search has shown that some substitutions have higher likelihood to be mimicked by modifications than others.

\section{Functional annotation of edited proteins found in shotgun proteomes}

To bare light on the purpose of RNA editing, all the peptides found to undergo editing shown in Table 1 were analyzed with the system of functional protein interactions (STRING, version $10.0 \mathrm{http}: / /$ string-db.org/)41. Figure 2 shows the STRING analysis results. There are two groups of proteins with highly confident interactions. These groups were selected and named by manual curation based on Gene Ontology biological process analysis. In this part, we avoided use of software that automatically calculated enrichment by particular GO terms, since, in our case, it was difficult to determine the reference group of genes for this analysis. 
First ("synaptic signaling" in the Fig. 2) group contains the following proteins: syntaxin (Syx1A), synaptotagmin (Syt1), complexin (cpx), synapsin (Syn), adaptin (AP-2 alpha), endophilin A (endoA), stoned protein B (StnB), Bruchpilot (brp), calciumdependent secretion activator (Cadps), and calcium ion channel subunit encoded by CG4587. These proteins play a role in synaptic transmission. Particularly, syntaxin and synaptotagmin are components of a SNARE complex that provides fusion of synaptic vesicles with the presynaptic membrane, complexin being additional important binder of this complex ${ }^{42}$. Stoned protein B also binds this complex and plays a role in synaptic vesicle endocytosis 43. Adaptins play a role in a process of synaptic vesicle recycling 44 . Endophilin (endoA) acts in the process of vesicle endocytosis in neuromuscular junction 45-48. Calcium-dependent secretion activator (Cadps) is a $\mathrm{Ca}^{2+}$-dependent factor of vesicle endocytosis 49,50 . The synaptic signaling group contains five proteins edited in all shotgun datasets, obviously representing most often edited protein products.

The second group ("cytoskeleton") of proteins consists of non-muscular myosin (zip), alpha-Spectrin (alpha-Spec), titin (sls), and other gene products (Fig. 2). All proteins from this group are either components of cytoskeleton or interact with them and take a part in cell transport processes. This group includes only one edited site identified in all three datasets studied which belongs to alpha-spectrin protein. 


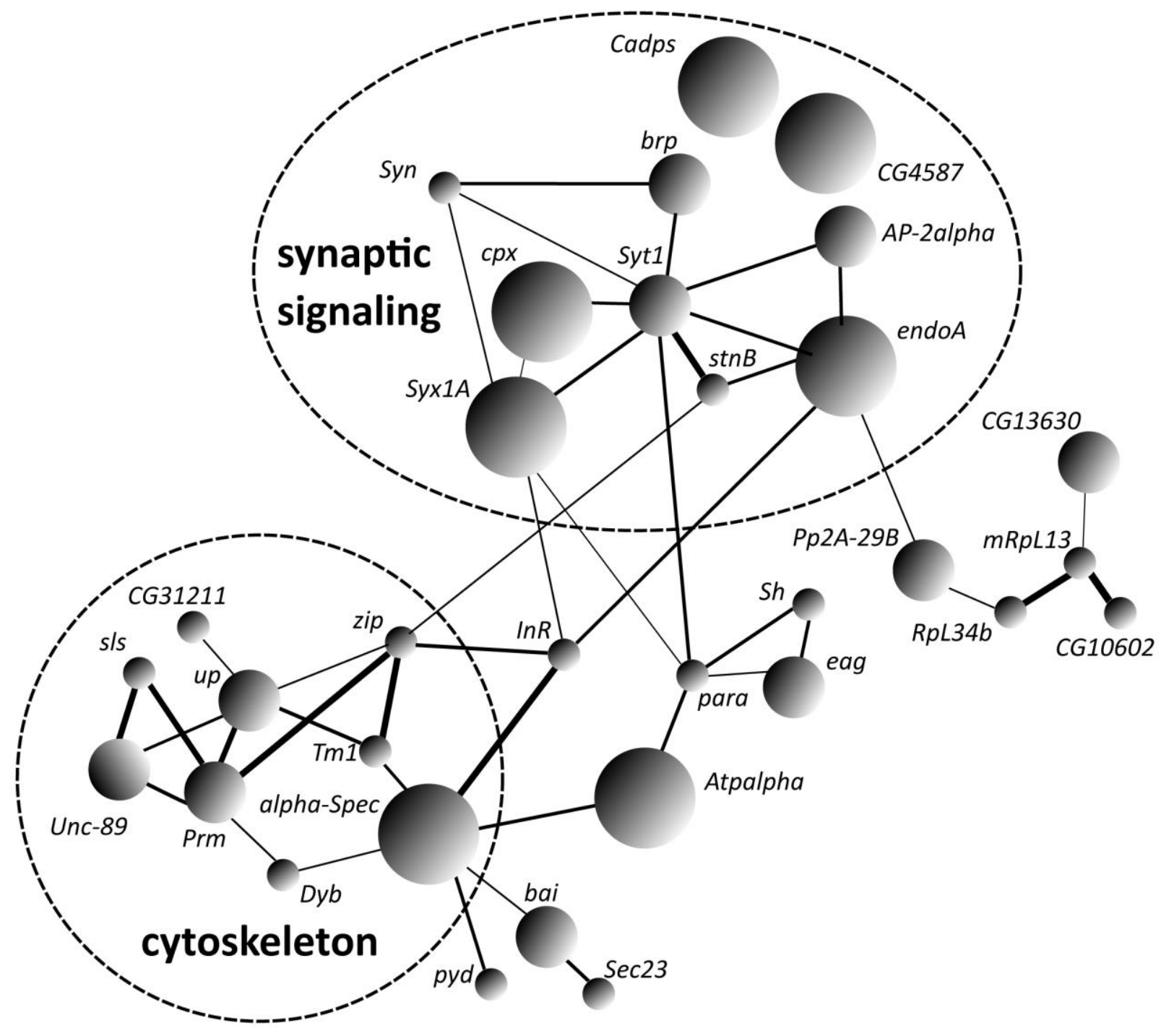

Figure 2. Interactions between proteins that undergo RNA editing. The size of the nods reflect the level of identification confidence in our analysis, the thickness of interaction lines shows the confidence of the interaction according to STRING.

Genotyping of genomic DNA sites corresponding to found RNA editing events 
Eight sites identified by shotgun proteome in all datasets used were further validated for A-to-I RNA editing at the level of nucleic acid. One site of RhoGAP1OoF gene found in two datasets was added to them due to close functional relation to other core edited proteins. Polymorphic sites of nine selected D. melanogaster genes (M244V in Syx1A, K398R in Atx2, Y390C in Atpalpha, R489G in CG4587, I125M in cpx, K137E in EndoA, Q170oR in AlphaSpec, M1234V in Cadps and Q1142R in RhoGAP1OoF) were genotyped. As a result, no traces of genetically encoded A-to-G substitutions were found which could probably mimic RNA editing events (Table 2). This finding confirms the assumption that the substitutions in nucleic acid, if they existed, happened posttranscriptionally.

\section{Identification of inosine sites on RNA strands by inosine chemical} erasing

Sites of nine genes selected as above were analyzed by inosine chemical erasing (ICE) method ${ }^{8}$. After comparison between cDNA sequencing from chemically erased $(\mathrm{CE}+)$ by acrylonitrile and intact (CE-) RNA, only in four of nine candidate sites, inosine-containing sites were confirmed by the chemical method including Atpalfa (chr3R:20965039:A/G:Y390C). Cadps $\quad$ (chr4:1265107:A/G:M>V). $\quad C p x$ (chr3R:4297504:A/G:I125M) and Syx1A (chr3R:24103714:A/G:M244V) (Table 2).

\section{Targeted validation and quantitation of edited sites at the protein level by Multiple Reaction Monitoring (MRM) with stable isotope labeled standards}


After shotgun analysis of a fruit fly editome on proteomic level a targeted analysis of the most interesting sites was held as a reasonable continuation of the study. We also intended to check the discrepancy between shotgun results and RNA study detected only five of nine sites of interest as inosine-containing.

For analysis, those sites present in all shotgun datasets were selected that were functionally related to synaptic function, more precisely, to pathways providing a fusion of the synaptic vesicle to the presynaptic cell membrane upon action potential ${ }^{51}$. These presumably edited proteins included syntaxin 1A (Syx1A) and complexin $(C p x)$ known as the participant and the binder of the SNARE complex, respectively ${ }^{52}$. Other proteins of interest included endophilin A (EndoA) providing membrane shaping in synapses45, Cadps and CG4587 involved in calcium signalling in presynaptic zone 49,53 and a GTPase activator. RhoGAP1OoF, participating the organization of presynaptic dense zone 54 . As mentioned above, this latter was added to the list for targeted analysis, in spite it was identified in two datasets only. Also, we added to the analysis a site of ataxin-2 (Atx2), well-studied protein with relevance to memory and other neural functions 55.

Currently, assays for targeted MS analyses are classified into three tiers, as described ${ }^{56}$. According to this classification, we could define a present study as Tier 2. In our work, first, we studied modified peptides in non-human samples using MRM method. Also, it was not a clinical research, but used stable isotope labelled synthetic internal standards which did not undergo purification.

As it was mentioned above, not every candidate site checked was confirmed on the RNA level. However, we included four of such failed sites to the group for validation by MRM. As it was shown in Table 2, targeted test in two cases confirmed ICE-seq RNA data (Atx2, RhoGAP1OoF), where no traces of edited or intact peptides were detected in 
the brain hydrolysates. In contrast, a good evidence was provided by MRM for sites of EndoA and CG4587 in both genome encoded and edited form, in spite no confirmation of these sites by RNA analysis. Stable isotope labelled standards of variant peptides for each site behaved similarly to naturally occurring products of the hydrolysed brain proteome in MRM tests (Fig. 3). This provided strong evidence of their chemical identity. Lack of detection of editing sites by inosine chemical erasing could be explained by low yield of desired products of the treatment for these certain sites. Otherwise, abundances of mRNA and protein products of the same gene are not always correlated, at least, if they are measured as a snapshot without temporal dependence 57. Hypothetically, RNA products of the genes of interest could be quickly destroyed during the procedures with animals. Finally, three sites were properly confirmed as edited in both transcriptome and proteome, which belonged to Cadps, Cpx and Syt1 genes. 
bioRxiv preprint doi: https://doi.org/10 1101/101949; this version posted July 17 2018. The copyright holder for this preprint (which was not certified by peer review) is the author/funder, who has granted bioRxiv a license to display the preprint in perpetuity. It is made available under aCC-BY 4.0 International license.

A
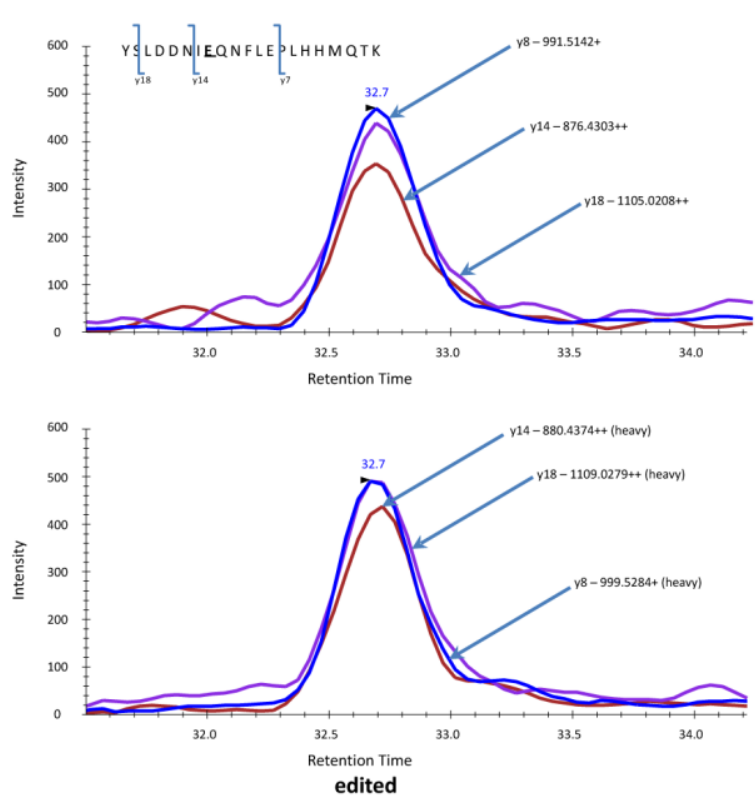

B
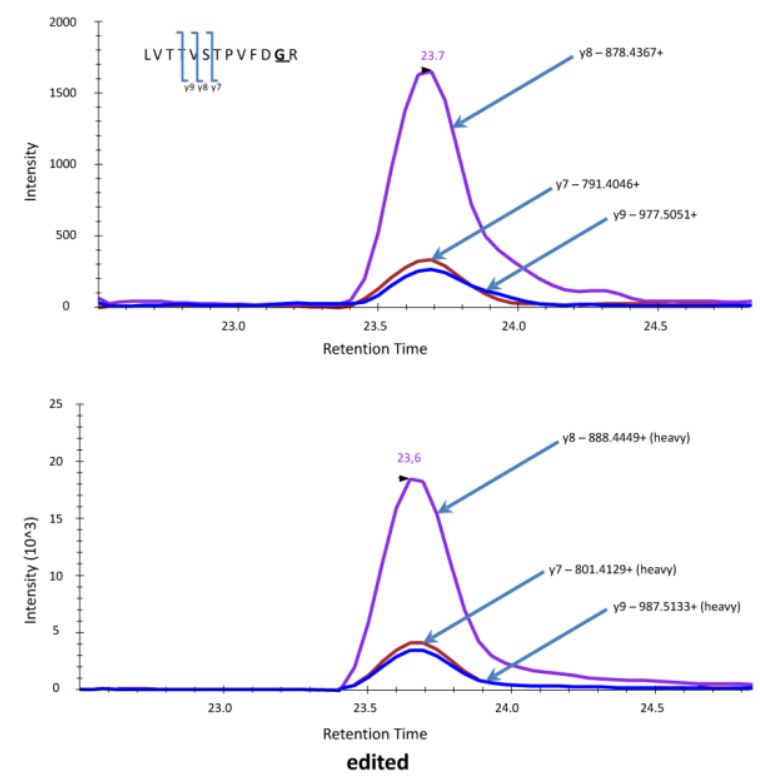

EndoA
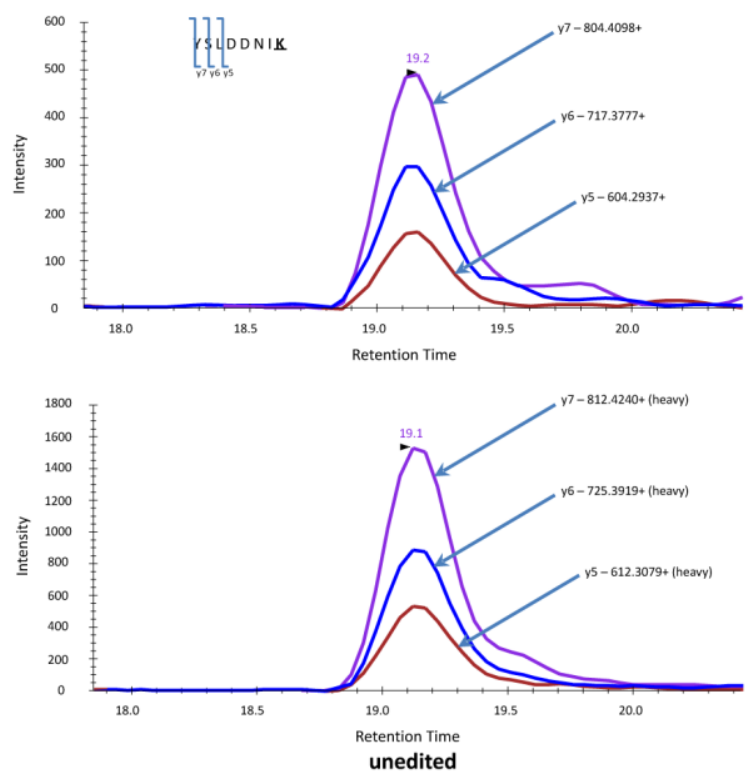

CG4587
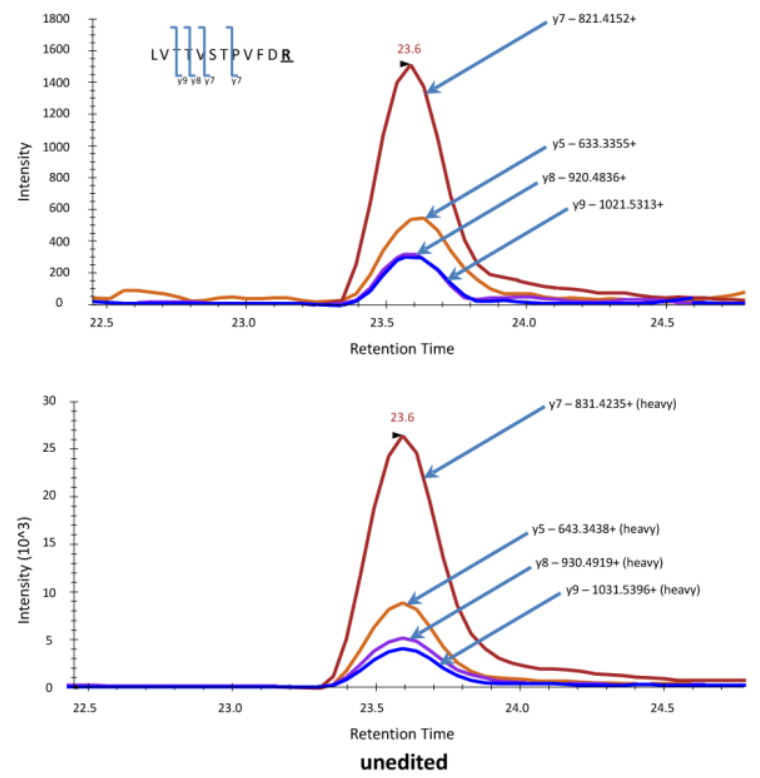

Figure 3. MRM spectra of edited and unedited variants of $C G 4587$ (A) and EndoA

(B) peptides. 
With labelled standards, we could measure absolute concentrations of targeted peptide in the brain samples. However, these levels may be influenced by many factors during multiple stages of sample preparation. According to our estimates, for five proteins of interest, these levels varied within one order of magnitude, from approximately 3.5 to $60 \mathrm{nmol} / \mathrm{g}$ of total protein in Cadps and EndoA, respectively (Fig. 4).

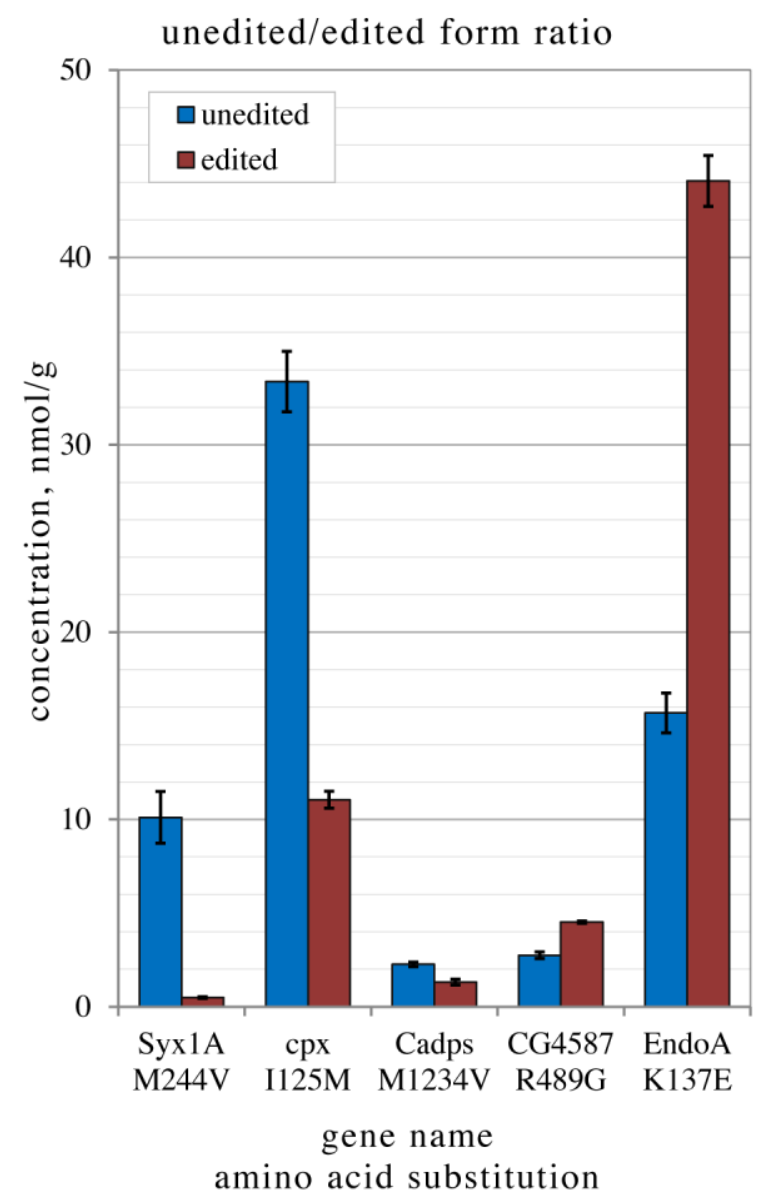

Figure 4. Concentrations of edited and unedited peptides of Syx1A, cpx, Cadps, CG4587 and EndoA measured by MRM. 
For aims of this work, it was more relevant to consider a ratio between genomic and edited forms of proteins which should be less dependent on sample preparation. This ratio was shown to be reproducible between two independent Canton-S fruit fly cultures (Figure S-11). At the same time, it varied between sites of interest. Thus, in syntaxin $1 \mathrm{~A}$, less than $5 \%$ of proteins occurred edited. Complexin, another member of SNARE complex was edited approximately by a quarter. Cadps product being edited by a third. Next, the $C G 4587$ calcium channel subunit and endophilin A sites were shown to be edited by $62 \%$ and $74 \%$, respectively (Table 3 ). The latter protein attracted special attention, as it was simultaneously most abundant and most edited of products studied.

\section{Discussion}

Shotgun proteomics after taking on board high-resolution mass-spectrometry gained success in identification and quantification of proteins as gene products, so called, master proteins. Today, LC-MS/MS analysis using high resolution mass spectrometry provides deep proteome covering about 50\% of human genome from a single sample 58,59. This ratio is even higher in model organisms which may be characterized by more open genomes with higher numbers of expressed proteins ${ }^{60}$. Correspondingly, a next aim of proteomics is to catalogue proteoforms of each protein. i.e. multiple protein species originated from one gene ${ }^{61,62}$. Here we catalogued proteoforms of the fruit fly that originated from coding events of RNA editing by ADAR enzymes.

Expectedly, not every amino acid substitution predicted from RNA data could be detected. Partly, it is the limit of detection which is much higher in proteomics than PCR-based genomics. Moreover, many of edited RNA may not be translated at all. It is 
hypothesised that ADAR enzyme originally marked two-chained RNA in struggle versus viral genomes. Today, the immune functions are generally associated with ADAR1, at least, in mammalian cells ${ }^{63}$. Thus, many RNAs edited may lose their stability and eliminated without being translated.

Besides probably the original antiviral function, ADARs can recode mRNA and proteins, thereby changing their properties. A well-studied example is a Gln-to-Arg substitution in mammalian ion channel glutamate receptor Gria2 which dramatically modulates their conductivity ${ }^{64}$. This protein recoding by ADAR better recognised in central neuron system and generally associated with ADAR2, at least, in mammals ${ }^{63}$. In our study, more likely, we encountered the functionally important recoding of proteins associated with synaptic function in the fruit fly.

Omics technologies are powerful instruments literally flooding researchers by qualitative and quantitative information. Thus, collecting transcriptome changes induced by its editing by ADARs, we checked their penetrance to the proteome level. However, we only can guess whether the changes identified are functional or represent a molecular noise as a side effect of the enzymatic activity. Although omics results are descriptive and cannot by themselves provide biological findings, they represent a good tool to hypothesize. Further we try to discuss the hypotheses that may result from validated proteomic data of ADAR-induced editome.

As mentioned above, syntaxin $1 \mathrm{a}$ is a component of the well-studied SNARE complex which provides fusion of presynaptic membrane and synaptic vesicles in most organism with neural system. SNARE is characterized structurally many times, especially, for model mammals ${ }^{65}$. In the complex, $\alpha$-spirals of four proteins including syntaxin form a bunch. The editing site found in syntaxin in this work, M244V, is 
situated, however, outside this spiral and is not mapped to any known functional site. The importance of this specific site is dubious due to the lesser extent of its editing which was not above $5 \%$.

Complexin is also a protein functionally related to SNARE complex. By binding to the bundle of $\alpha$-spirals of the complex by its own spiral it prevents spontaneous fusion of vesicles with the membrane in absence of calcium signaling66. The I125M site, however, is located in the C-terminus of the molecule which is not conservative between rodents and insects. In rat, this part of complexin molecule provides membrane binding66. Hypothetically, the substitution caused by editing in complexin of the fruit fly may modulate affinity of protein-membrane interaction.

The Calcium-Dependent Secretion Activator (CADPS, or CAPS) expressed by Cadps gene acts from the other side of SNARE complex being connected with synaptic vesicles and activating them in presence of calcium ions49. CAPS was originally proposed to bind the SNARE complex after priming synaptic vesicles, but later its mechanism of action was shown to be SNARE-independent ${ }^{67}$. We have shown that more than a third of this protein was subjected to M1234V editing. However, this substitution could be not interpreted from the position of spatial structure or domain function. Notably, human and mouse orthologs of Cadps are known to be extensively edited by ADAR enzyme. According to RADAR database, each of these genes is edited in tens sites, at least two of them coding amino acid substitutions ${ }^{29}$. These latter are although not overlap the site edited in the fruit fly.

The product of the gene $C G 4587$ is a protein engaged in $\mathrm{Ca}^{2+-}$ dependent nociception response 53. Little is known about its spatial structure, such that it is difficult to propose a role of the $\mathrm{R} 489 \mathrm{G}$ substitution. There is some parallel of this type 
of substitution with the mammalian editome where glutamate ion channel subunits (Gria2, Gria4) also bear a similar amino acid change 64 . Moreover, as in the case of CAPS protein, a human ortholog of CG4587 called a voltage-dependent calcium channel subunit alpha-2/delta-4 (CACNA2D4) also is edited, although in the intronic region ${ }^{68}$. Notably, based on our data, yet undiscovered importance of this gene product could be deduced. CG4587 protein shares about 30\% identity with its important paralog, Straitjacket (stj), which is another $\mathrm{Ca}^{2+-}$ dependent channel subunit, also involved in nociception ${ }^{69}$. Straitjacket is not in our list of the proteins corresponding to the RNA editing event, but it was found in the fruit fly proteome and identified by search engines in our data. Theoretically, stj may correspond to the editing event, because its transcript was prone to editing by ADAR and the protein was in our customized database (Supplemental files 5 and 6). The fact that stj did not listed among the identified edited proteins could be explained by its underrepresentation in the spectra compared to CG4587. The head and brain proteomes are of the most interest in terms of the expression of the $\mathrm{Ca}^{2+}$-dependent channels. In the brain proteome, the relative intensity of stj calculated by MaxQuant search engine is 34.7 times lower compared with CG4587. Label-free quantification (LFQ) obtained for X!tandem search results has shown the following results for $C G 4587 /$ stj LFQ ratios: $12.4,4.7$ and 6.6 for SIN 70, NSAF 71, and emPAI ${ }^{72}$ LFQ algorithms, respectively. For the whole head proteome, the $C G 4587 / s t j$ ratios were 5.4, 4.4, and 8.5 for these LFQ algorithms, respectively. Therefore, even though straitjacket is an important and well-characterized protein of nervous tissue, its paralog, CG4587 gene product had significantly higher abundance in the proteomes of isolated brain, as well as the whole head. Along with the Straitjacket protein, this subunit deserves further functional studies. 
Unlike of all other sites of interest which lacked structural information, we were luckier with endophilin A editing site, where lysine-137 was substituted to glutamate with a high yield of $74 \%$ (Table 3 ). This residue is located inside the $\alpha 2$-spiral of conserved and well-studied BAR domain of this protein 73. Domains of this type form dimers and are contained many proteins associated with intercellular membrane dynamics 74 . It was shown that BAR domain in endophilin A provided the membrane curvature binding hydrophilic surface of lipid bilayer by concaved surface of its dimer 75 . A residue of interest is located close to this surface or on it, as it can be seen from the spatial structure of human protein, which in this part is almost identical to that of Drosophila (Figure 5). The affinity between membrane and endophilin A BAR domain is provided inter alia by electrostatic interactions between negatively charged phospholipid heads and lysine residues on the concave part. Thus, one can hypothesise that a recharging Lys-to-Glu substitution in endophilin A may dramatically influence the binding affinity of the protein with membrane, whereby regulating membrane dynamics in neural cells. This finding can be verified by experiments with recombinant proteins and model membranes. The impact of endophilin A editing on the insect organism may be verified by generation of corresponding mutant strains. 


\section{Endophilin A}

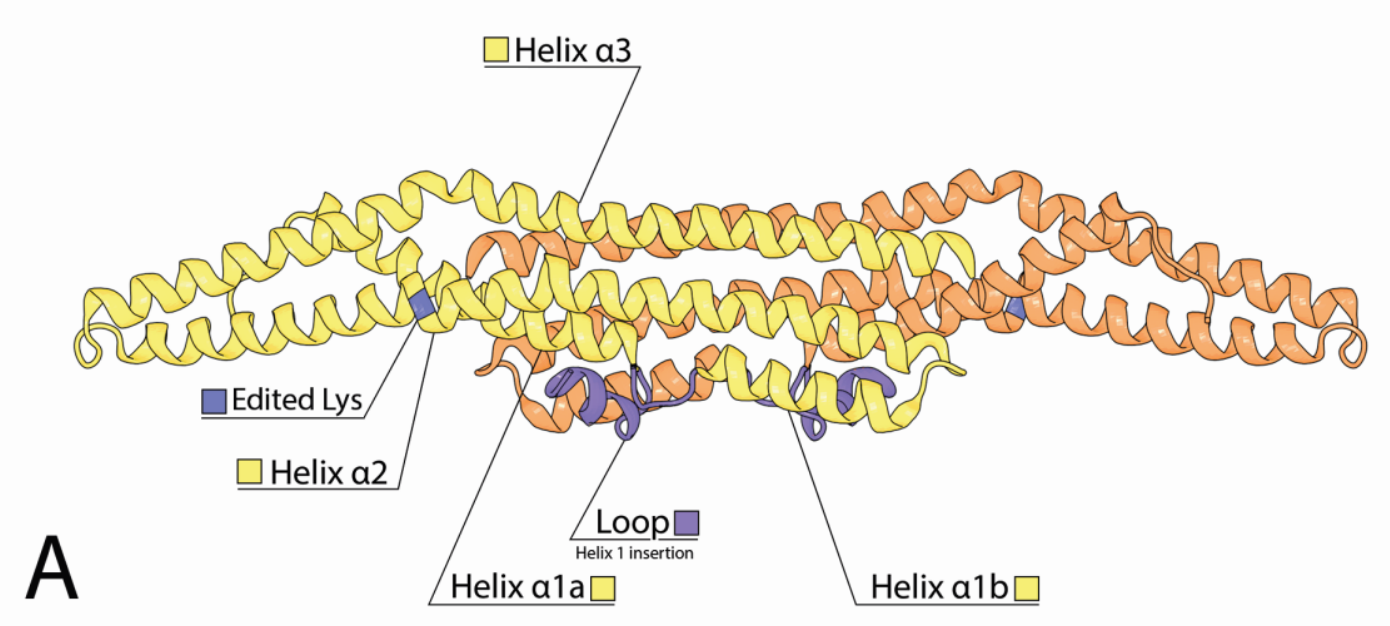

E

Drosophila melanogaster YYSLDDNIKQNFLEPLHHMQTKDLKEVMHHRKKLLQGRRLDFD

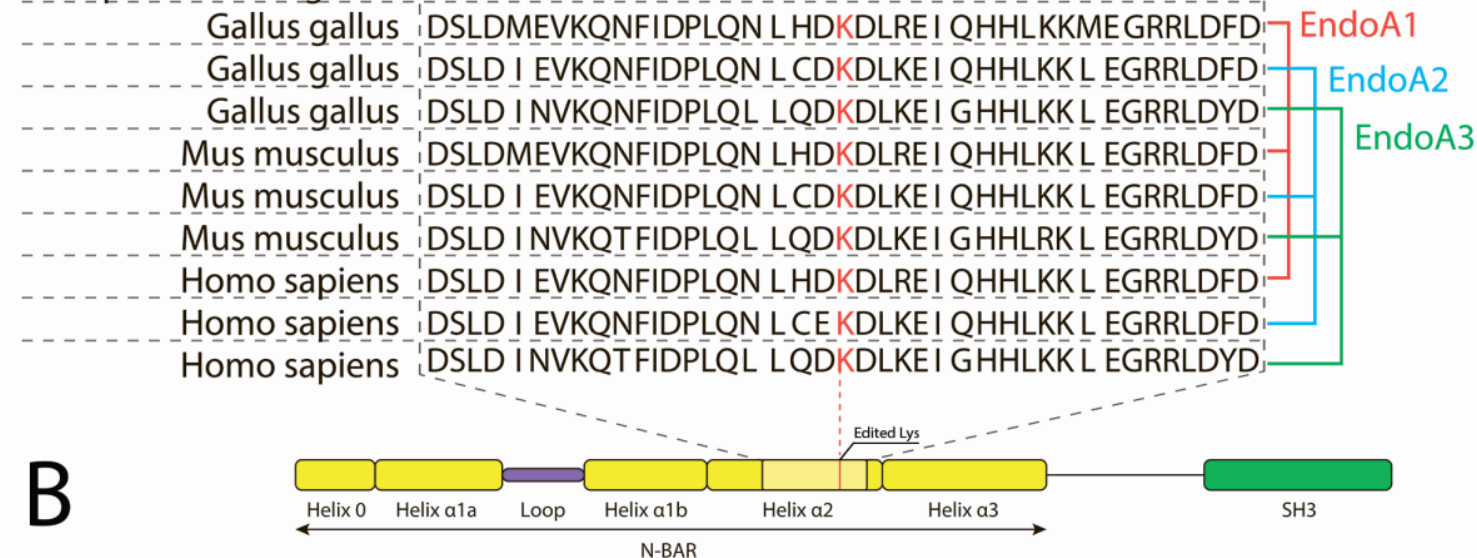

Figure 5. A lysine edited to glutamic acid in fruit fly endophilin A in the spatial structure of BAR domain.

A. Homologous position of conservative lysine residue corresponding to Lys-137 of fruit fly EndoA shown in the dimer of BAR domains of the human ortholog (PDB accession 1Xo3) [Masuda et al.] 74 Structural elements of BAR domain are designated as described [Weissenhorn] 72 . 
B. Local alignments between fruit fly EndoA product and endophilin A isoforms of chicken, mouse and human illustrate a high level of conservation in $\alpha 2$ helix between animals.

Notably, endophilin A transcripts in mammals are shown to be edited by ADAR enzymes, but in their intronic parts. In the contrary, for the fruit fly we observed massive recoding of the protein sequence, which, obviously, should have a functional impact. Recently, it was suggested that A-to-I editing in Protostomia could tune functions of proteins instead of genomic mutations ${ }^{15}$. What if the endoA editing in the fruit fly was functionally compensated in vertebrates by evolutional creation of three gene paralogs for endophilin A?

In this work, we identified consequences of adenosine-to-inosine RNA editing in shotgun proteomes of Drosophila melanogaster, validated and quantified selected edited sites by targeted proteomics of the brain tissue. Some of proteins with known neural function, for example, endophilin A, were shown to be substantially edited in the insect brain. Thus, our omics experiments provided some sound and testable hypotheses, which could be further verified by orthogonal biochemical methods.

\section{Acknowledgements}

The work was funded by the Russian Scientific Foundation, grant \# 17-15-01229.

Authors thank Dr. Natalia Romanova from the Department of Genetics of Biological Faculty of Moscow State University for providing the Drosophila melanogaster Canton S stock and Dr. Leonid Kurbatov from the Institute of Biomedical Chemistry for technical assistance. 


\section{References}

(1) Benne R, Burg JVD, Brakenhoff JPJ, Sloof P, Boom JHV, et al. Major Transcript of the Frameshifted CoxII Gene from Try- Panosome Mitochondria Contains Four Nu- Cleotides That Are Not Encoded in the DNA. Cell 1986, 46, 819-26.

(2) Gott, J. M.; Emeson, R. B. Functions and Mechanisms of RNA Editing. Annu. Rev. Genet. 2000, 34, 499-531.

(3) Blanc, V.; Davidson, N. O. C-to-U RNA Editing: Mechanisms Leading to Genetic Diversity. J. Biol. Chem. 2oo3, 278 (3), 1395-1398.

(4) Bass, B. L.; Weintraub, H. An Unwinding Activity That Covalently Modifies Its Double-Stranded RNA Substrate. Cell 1988, 55 (6), 1089-1098.

(5) Kim, U.; Wang, Y.; Sanford, T.; Zeng, Y.; Nishikura, K. Molecular Cloning of CDNA for Double-Stranded RNA Adenosine Deaminase, a Candidate Enzyme for Nuclear RNA Editing. Proc. Natl. Acad. Sci. U. S. A. 1994, 91 (24), 11457-11461.

(6) Shikanai, T. RNA Editing in Plants: Machinery and Flexibility of Site Recognition. Biochimica et biophysica acta. September 2015, pp 779-785.

(7) Takenaka, M.; Verbitskiy, D.; Zehrmann, A.; Härtel, B.; Bayer-Császár, E.; Glass, F.; Brennicke, A. RNA Editing in Plant Mitochondria -Connecting RNA Target Sequences and Acting Proteins. Mitochondrion 2014, 19 (PB), 191-197.

(8) Seeburg, P. H. A-to-I Editing: New and Old Sites, Functions and Speculations. Neuron. 2002, pp 17-20.

(9) He, T.; Wang, Q.; Feng, G.; Hu, Y.; Wang, L.; Wang, Y. Computational Detection and Functional Analysis of Human Tissue-Specific A-to-I RNA Editing. PLoS One 2011, $6(3), 1-7$. 
(10) Vissel, B.; Royle, G. A.; Christie, B. R.; Schiffer, H. H.; Ghetti, A.; Tritto, T.; Perez-

Otano, I.; Radcliffe, R. A.; Seamans, J.; Sejnowski, T.; et al. The Role of RNA

Editing of Kainate Receptors in Synaptic Plasticity and Seizures. Neuron 2001, 29

(1), 217-227.

(11) Egebjerg, J.; Heinemann, S. F. Ca2+ Permeability of Unedited and Edited

Versions of the Kainate Selective Glutamate Receptor GluR6. Proc. Natl. Acad.

Sci. U. S. A. 1993, 90 (2), 755-759.

(12) Rieder, L. E.; Savva, Y. a; Reyna, M. a; Chang, Y.-J.; Dorsky, J. S.; Rezaei, A.;

Reenan, R. a. Dynamic Response of RNA Editing to Temperature in Drosophila.

BMC Biol. 2015, 13.

(13) Low, T. Y.; vanHeesch, S.; vandenToorn, H.; Giansanti, P.; Cristobal, A.; Toonen, P.; Schafer, S.; Hübner, N.; vanBreukelen, B.; Mohammed, S.; et al. Quantitative and Qualitative Proteome Characteristics Extracted from In-Depth Integrated Genomics and Proteomics Analysis. Cell Rep. 2013, 5 (5), 1469-1478.

(14) Picardi, E.; Manzari, C.; Mastropasqua, F.; Aiello, I.; D’Erchia, A. M.; Pesole, G. Profiling RNA Editing in Human Tissues: Towards the Inosinome Atlas. Sci. Rep.

2015, 5, 14941.

(15) Liscovitch-Brauer, N.; Alon, S.; Porath, H. T.; Elstein, B.; Unger, R.; Ziv, T.;

Admon, A.; Levanon, E. Y.; Rosenthal, J. J. C.; Eisenberg, E. Trade-off between Transcriptome Plasticity and Genome Evolution in Cephalopods. Cell 2017, 169 (2), 191-202.e11.

(16) Peng, X.; Xu, X.; Wang, Y.; Hawke, D. H.; Yu, S.; Han, L.; Zhou, Z.; Mojumdar, K.; Jeong, K. J.; Labrie, M.; et al. A-to-I RNA Editing Contributes to Proteomic Diversity in Cancer. Cancer Cell 2018, 1-12. 
(17) Nesvizhskii, A. I. Proteogenomics: Concepts, Applications and Computational Strategies. Nat. Methods 2014, 11 (11), 1114-1125.

(18) Zhao, H.; Zhang, P.; Gao, H.; He, X.; Dou, Y.; Huang, A. Y.; Liu, X.; Ye, A. Y.;

Dong, M.; Wei, L. Profiling the RNA Editomes of Wild-Type C. Elegans and ADAR Mutants. Genome Res. 2015, 25 (1), 66-75.

(19) Chernobrovkin, A. L.; Kopylov, A. T.; Zgoda, V. G.; Moysa, A. A.; Pyatnitskiy, M. A.; Kuznetsova, K. G.; Ilina, I. Y.; Karpova, M. A.; Karpov, D. S.; Veselovsky, A. V; et al. Methionine to Isothreonine Conversion as a Source of False Discovery Identifications of Genetically Encoded Variants in Proteogenomics. J. Proteomics 2015, 12O, 169-178.

(20) Hoopengardner, B.; Bhalla, T.; Staber, C.; Reenan, R. Nervous System Targets of RNA Editing Identified by Comparative Genomics. Science 2003, 301 (2003), $832-836$.

(21) Rodriguez, J.; Menet, J. S.; Rosbash, M. Nascent-Seq Indicates Widespread Cotranscriptional RNA Editing in Drosophila. Mol. Cell 2012, 47 (1), 27-37.

(22) Stapleton, M.; Carlson, J. W.; Celniker, S. E. RNA Editing in Drosophila Melanogaster: New Targets and Functional Consequences. $R N A$ 2oo6, 12 (11), $1922-1932$.

(23) St Laurent, G.; Tackett, M. R.; Nechkin, S.; Shtokalo, D.; Antonets, D.; Savva, Y. a; Maloney, R.; Kapranov, P.; Lawrence, C. E.; Reenan, R. a. Genome-Wide Analysis of A-to-I RNA Editing by Single-Molecule Sequencing in Drosophila. Nat. Struct. Mol. Biol. 2013, 20 (11), 1333-1339.

(24) Yu, Y.; Zhou, H.; Kong, Y.; Pan, B.; Chen, L.; Wang, H.; Hao, P.; Li, X. The Landscape of A-to-I RNA Editome Is Shaped by Both Positive and Purifying 
Selection. PLOS Genet. 2016, 12 (7), e1006191.

(25) Lobas, A. A.; Karpov, D. S.; Kopylov, A. T.; Solovyeva, E. M.; Ivanov, M. V; Ilina, I.

I.; Lazarev, V. N.; Kuznetsova, K. G.; Ilgisonis, E. V; Zgoda, V. G.; et al. Exome-

Based Proteogenomics of HEK-293 Human Cell Line: Coding Genomic Variants

Identified at the Level of Shotgun Proteome. Proteomics 2016, 1-12.

(26) Xing, X.; Zhang, C.; Li, N.; Zhai, L.; Zhu, Y.; Yang, X.; Xu, P. Qualitative and

Quantitative Analysis of the Adult Drosophila Melanogaster Proteome.

Proteomics 2014, 14, 286-290.

(27) Aradska, J.; Bulat, T.; Sialana, F. J.; Birner-Gruenberger, R.; Erich, B.; Lubec, G.

Gel-Free Mass Spectrometry Analysis of Drosophila Melanogaster Heads.

Proteomics 2015, 15 (19), 3356-3360.

(28) Vizcaíno, J.; Deutsch, E. E. W.; Wang, R.; Vizcaino, J. A.; Deutsch, E. E. W.;

Wang, R.; Csordas, A.; Reisinger, F.; Rios, D.; Dianes, J. A.; et al.

ProteomeXchange Provides Globally Coordinated Proteomics Data Submission and Dissemination. Nat Biotech 2014, 32 (3), 223-226.

(29) Ramaswami, G.; Li, J. B. RADAR: A Rigorously Annotated Database of A-to-I RNA Editing. Nucleic Acids Res. 2014, 42 (D1), 109-113.

(30) Gramates, L. S.; Marygold, S. J.; Dos Santos, G.; Urbano, J. M.; Antonazzo, G.;

Matthews, B. B.; Rey, A. J.; Tabone, C. J.; Crosby, M. A.; Emmert, D. B.; et al. FlyBase at 25: Looking to the Future. Nucleic Acids Res. 2017, 45 (D1), D663D671.

(31) Neuhauser, N.; Nagaraj, N.; McHardy, P.; Zanivan, S.; Scheltema, R.; Cox, J.; Mann, M. High Performance Computational Analysis of Large-Scale Proteome Data Sets to Assess Incremental Contribution to Coverage of the Human Genome. 
J. Proteome Res. 2013, 12 (6), 2858-2868.

(32) Craig, R.; Beavis, R. C. TANDEM: Matching Proteins with Tandem Mass Spectra. Bioinformatics 2004, 20 (9), 1466-1467.

(33) Levitsky, L. I.; Ivanov, M. V.; Lobas, A. A.; Gorshkov, M. V. Unbiased False Discovery Rate Estimation for Shotgun Proteomics Based on the Target-Decoy Approach. J. Proteome Res. 2017, 16 (2), 393-397.

(34) Goloborodko, A. A.; Levitsky, L. I.; Ivanov, M. V.; Gorshkov, M. V. Pyteomics - A Python Framework for Exploratory Data Analysis and Rapid Software Prototyping in Proteomics. J. Am. Soc. Mass Spectrom. 2013, 24 (2), 301-304.

(35) Hood, C. A.; Fuentes, G.; Patel, H.; Page, K.; Menakuru, M.; Park, J. H. Fast Conventional Fmoc Solid-Phase Peptide Synthesis with HCTU. J. Pept. Sci. 2oo8, $14(1), 97-101$.

(36) Farrah, T.; Deutsch, E. W.; Kreisberg, R.; Sun, Z.; Campbell, D. S.; Mendoza, L.; Kusebauch, U.; Brusniak, M. Y.; Hüttenhain, R.; Schiess, R.; et al. PASSEL: The PeptideAtlas SRMexperiment Library. Proteomics 2012, 12 (8), 1170-1175.

(37) Sambrook, J.; Fritsch, E.; Maniatis, T. Molecular Cloning: A Laboratory Manual.; Elsevier, 1989.

(38) Sakurai, M.; Yano, T.; Kawabata, H.; Ueda, H.; Suzuki, T. Inosine Cyanoethylation Identifies A-to-I RNA Editing Sites in the Human Transcriptome. Nat. Chem. Biol. 2010, 6 (10), 733-740.

(39) Sheynkman, G. M.; Shortreed, M. R.; Cesnik, A. J.; Smith, L. M. Proteogenomics: Integrating Next-Generation Sequencing and Mass Spectrometry to Characterize Human Proteomic Variation. Annu. Rev. Anal. Chem. 2016, 9 (1), annurevanchem-071015-041722. 
(40) Moshkovskii, S. A.; Ivanov, M. V; Kuznetsova, K. G.; Gorshkov, M. V.

Identification of Single Amino Acid Substitutions in Proteogenomics. 2018, 83

(3), 250-258.

(41) Szklarczyk, D.; Morris, J. H.; Cook, H.; Kuhn, M.; Wyder, S.; Simonovic, M.;

Santos, A.; Doncheva, N. T.; Roth, A.; Bork, P.; et al. The STRING Database in 2017: Quality-Controlled Protein-Protein Association Networks, Made Broadly Accessible. Nucleic Acids Res. 2017, 45 (D1), D362-D368.

(42) Wang, Z.; Chapman, E. R. Rat and Drosophila Synaptotagmin 4 Have Opposite Effects during SNARE-Catalyzed Membrane Fusion. J. Biol. Chem. 2010, 285 (40), 30759-30766.

(43) Fergestad, T.; Broadie, K. Interaction of Stoned and Synaptotagmin in Synaptic Vesicle Endocytosis. J. Neurosci. 2001, 21 (4), 1218-1227.

(44) González-Gaitán, M.; Jäckle, H. Role of Drosophila a-Adaptin in Presynaptic Vesicle Recycling. Cell 1997, 88 (6), 767-776.

(45) Guichet, A.; Wucherpfennig, T.; Dudu, V.; Etter, S.; Wilsch-Bräuniger, M.; Hellwig, A.; González-Gaitán, M.; Huttner, W. B.; Schmidt, A. A. Essential Role of Endophilin A in Synaptic Vesicle Budding at the Drosophila Neuromuscular Junction. EMBO J. 2002, 21 (7), 1661-1672.

(46) Verstreken, P.; Kjaerulff, O.; Lloyd, T. E.; Atkinson, R.; Zhou, Y.; Meinertzhagen, I. A.; Bellen, H. J. Endophilin Mutations Block Clathrin-Mediated Endocytosis but Not Neurotransmitter Release. Cell 2002, 109 (1), 101-112.

(47) Coyle, I. P.; Koh, Y. H.; Lee, W. C. M.; Slind, J.; Fergestad, T.; Littleton, J. T.; Ganetzky, B. Nervous Wreck, an SH3 Adaptor Protein That Interacts with Wsp, Regulates Synaptic Growth in Drosophila. Neuron 2oo4, 41 (4), 521-534. 
(48) Li, W.; Yao, A.; Zhi, H.; Kaur, K.; Zhu, Y. C.; Jia, M.; Zhao, H.; Wang, Q.; Jin, S.;

Zhao, G.; et al. Angelman Syndrome Protein Ube3a Regulates Synaptic Growth and Endocytosis by Inhibiting BMP Signaling in Drosophila. PLoS Genet. 2016, $12(5)$, e1006062.

(49) Renden, R.; Berwin, B.; Davis, W.; Ann, K.; Chin, C. T.; Kreber, R.; Ganetzky, B.;

Martin, T. F. J.; Broadie, K. Drosophila CAPS Is an Essential Gene That Regulates

Dense-Core Vesicle Release and Synaptic Vesicle Fusion. Neuron 2oo1, 31 (3), $421-437$.

(50) Pongs, O.; Lindemeier, J.; Zhu, X. R.; Theil, T.; Engelkamp, D.; Krah-Jentgens, I.;

Lambrecht, H.; Koch, K. W.; Schwemer, J.; Rivosecchi, R.; et al. Frequenin-A

Novel Calcium-Binding Protein That Modulates Synaptic Efficacy in the

Drosophila Nervous System. Neuron 1993, 11 (1), 15-28.

(51) Sollner, T.; Whiteheart, S. W.; Brunner, M.; Erdjument-Bromage, H.; Geromanos, S.; Tempst, P.; Rothman, J. E. SNAP Receptors Implicated in Vesicle Targeting and Fusion. Nature 1993, 362 (6418), 318-324.

(52) Hu, K.; Carroll, J.; Rickman, C.; Davletov, B. Action of Complexin on SNARE Complex. J. Biol. Chem. 2oo2, 277 (44), 41652-41656.

(53) Neely, G. G.; Keene, A. C.; Duchek, P.; Chang, E. C.; Wang, Q. P.; Aksoy, Y. A.; Rosenzweig, M.; Costigan, M.; Woolf, C. J.; Garrity, P. A.; et al. TrpA1 Regulates Thermal Nociception in Drosophila. PLoS One 2011, 6 (8), e24343.

(54) Owald, D.; Khorramshahi, O.; Gupta, V. K.; Banovic, D.; Depner, H.; Fouquet, W.; Wichmann, C.; Mertel, S.; Eimer, S.; Reynolds, E.; et al. Cooperation of Syd-1 with Neurexin Synchronizes Pre- with Postsynaptic Assembly. Nat. Neurosci. 2012, 15 (9), 1219-1226. 
(55) Bakthavachalu, B.; Huelsmeier, J.; Sudhakaran, I. P.; Hillebrand, J.; Singh, A.;

Petrauskas, A.; Thiagarajan, D.; Sankaranarayanan, M.; Mizoue, L.; Anderson, E.

N.; et al. RNP-Granule Assembly via Ataxin-2 Disordered Domains Is Required

for Long-Term Memory and Neurodegeneration. Neuron 2018, 98 (4), 754766.e4.

(56) Carr, S. A.; Abbatiello, S. E.; Ackermann, B. L.; Borchers, C.; Domon, B.; Deutsch, E. W.; Grant, R. P.; Hoofnagle, A. N.; Hüttenhain, R.; Koomen, J. M.; et al.

Targeted Peptide Measurements in Biology and Medicine: Best Practices for Mass Spectrometry-Based Assay Development Using a Fit-for-Purpose Approach. Mol. Cell. Proteomics 2014, 13 (3), 907-917.

(57) Liu, Y.; Beyer, A.; Aebersold, R. On the Dependency of Cellular Protein Levels on MRNA Abundance. Cell 2016, 165 (3), 535-550.

(58) Mann, M.; Kulak, N. A.; Nagaraj, N.; Cox, J. The Coming Age of Complete, Accurate, and Ubiquitous Proteomes. Mol. Cell 2013, 49 (4), 583-590.

(59) Chick, J. M.; Kolippakkam, D.; Nusinow, D. P.; Zhai, B.; Rad, R.; Huttlin, E. L.; Gygi, S. P. A Mass-Tolerant Database Search Identifies a Large Proportion of Unassigned Spectra in Shotgun Proteomics as Modified Peptides. Nat. Biotechnol. 2015, 33 (7), 743-749.

(6o) Nagaraj, N.; Kulak, N. A.; Cox, J.; Neuhauser, N.; Mayr, K.; Hoerning, O.; Vorm, O.; Mann, M. System-Wide Perturbation Analysis with Nearly Complete Coverage of the Yeast Proteome by Single-Shot Ultra HPLC Runs on a Bench Top Orbitrap. Mol. Cell. Proteomics 2012, 11 (3), M111.013722.

(61) Toby, T. K.; Fornelli, L.; Kelleher, N. L. Progress in Top-Down Proteomics and the Analysis of Proteoforms. Annu. Rev. Anal. Chem. 2016, 9 (1), 499-519. 
(62) Lisitsa, A.; Moshkovskii, S.; Chernobrovkin, A.; Ponomarenko, E.; Archakov, A. Profiling Proteoforms: Promising Follow-up of Proteomics for Biomarker Discovery. Expert Rev. Proteomics 2014, 11 (1), 121-129.

(63) Gallo, A.; Vukic, D.; Michalík, D.; O’Connell, M. A.; Keegan, L. P. ADAR RNA Editing in Human Disease; More to It than Meets the I. Hum. Genet. 2017, 136 (9), 1265-1278.

(64) Filippini, A.; Bonini, D.; La Via, L.; Barbon, A. The Good and the Bad of Glutamate Receptor RNA Editing. Mol. Neurobiol. 2017, 54 (9), 6795-6805.

(65) Chen, X.; Tomchick, D. R.; Kovrigin, E.; Araç, D.; Machius, M.; Südhof, T. C.; Rizo, J. Three-Dimensional Structure of the Complexin/SNARE Complex. Neuron 2002, 33 (3), 397-409.

(66) Zdanowicz, R.; Kreutzberger, A.; Liang, B.; Kiessling, V.; Tamm, L. K.; Cafiso, D. S. Complexin Binding to Membranes and Acceptor T-SNAREs Explains Its Clamping Effect on Fusion. Biophys. J. 2017, 113 (6), 1235-1250.

(67) Nguyen Truong, C. Q.; Nestvogel, D.; Ratai, O.; Schirra, C.; Stevens, D. R.; Brose, N.; Rhee, J.; Rettig, J. Secretory Vesicle Priming by CAPS Is Independent of Its SNARE-Binding MUN Domain. Cell Rep. 2014, 9 (3), 902-909.

(68) Ramaswami, G.; Zhang, R.; Piskol, R.; Keegan, L. P.; Deng, P.; O’Connell, M. A.; Li, J. B. Identifying RNA Editing Sites Using RNA Sequencing Data Alone. Nat. Methods 2013, 10 (2), 128-132.

(69) Neely, G. G.; Hess, A.; Costigan, M.; Keene, A. C.; Goulas, S.; Langeslag, M.; Griffin, R. S.; Belfer, I.; Dai, F.; Smith, S. B.; et al. A Genome-Wide Drosophila Screen for Heat Nociception Identifies A2 $\delta 3$ as an Evolutionarily Conserved Pain Gene. Cell 2010, 143 (4), 628-638. 
(70) Griffin, N. M.; Yu, J.; Long, F.; Oh, P.; Shore, S.; Li, Y.; Koziol, J. A.; Schnitzer, J. E. Label-Free, Normalized Quantification of Complex Mass Spectrometry Data for Proteomic Analysis. Nat Biotechnol 2010, 28 (1), 83-89.

(71) Paoletti, A. C.; Parmely, T. J.; Tomomori-Sato, C.; Sato, S.; Zhu, D.; Conaway, R. C.; Conaway, J. W.; Florens, L.; Washburn, M. P. Quantitative Proteomic Analysis of Distinct Mammalian Mediator Complexes Using Normalized Spectral Abundance Factors. Proc Natl Acad Sci U S A 2006, 103 (50), 18928-18933.

(72) Ishihama, Y.; Oda, Y.; Tabata, T.; Sato, T.; Nagasu, T.; Rappsilber, J.; Mann, M. Exponentially Modified Protein Abundance Index (EmPAI) for Estimation of Absolute Protein Amount in Proteomics by the Number of Sequenced Peptides per Protein. Mol. Cell. Proteomics 2005, 4 (9), 1265-1272.

(73) Weissenhorn, W. Crystal Structure of the Endophilin-A1 BAR Domain. J. Mol. Biol. 2005, 351 (3), 653-661.

(74) Stanishneva-Konovalova, T. B.; Derkacheva, N. I.; Polevova, S. V; Sokolova, O. S. The Role of BAR Domain Proteins in the Regulation of Membrane Dynamics. Acta Naturae 8 (4), 60-69.

(75) Masuda, M.; Takeda, S.; Sone, M.; Ohki, T.; Mori, H.; Kamioka, Y.; Mochizuki, N. Endophilin BAR Domain Drives Membrane Curvature by Two Newly Identified Structure-Based Mechanisms. EMBO J. 2006, 25 (12), 2889-2897. 
Table 1. The edited peptides found in Aradska et al. ${ }^{27}$, Xing et al. ${ }^{26}$, and in our data. The tiers of confidence are highlighted.

\begin{tabular}{|c|c|c|c|c|c|c|c|c|c|c|c|c|c|}
\hline sequence & gene & protein & $\begin{array}{l}\text { aa } \\
\text { substit } \\
\text { ution }\end{array}$ & $\begin{array}{c}\text { Aradska } \\
\text { et al. } \\
\text { RADAR }\end{array}$ & $\begin{array}{c}\text { Aradska } \\
\text { et al. } \\
\text { TIER1 }\end{array}$ & $\begin{array}{c}\text { Aradska } \\
\text { et al. } \\
\text { TIER2 }\end{array}$ & $\begin{array}{c}\text { Xing et } \\
\text { al. } \\
\text { RADAR }\end{array}$ & $\begin{array}{l}\text { Xing } \\
\text { et al. } \\
\text { TIER1 }\end{array}$ & $\begin{array}{l}\text { Xing } \\
\text { et al. } \\
\text { TIER2 }\end{array}$ & $\begin{array}{c}\text { our } \\
\text { data } \\
\text { RADAR }\end{array}$ & $\begin{array}{c}\text { our } \\
\text { data } \\
\text { TIER1 }\end{array}$ & $\begin{array}{c}\text { our } \\
\text { data } \\
\text { TIER2 }\end{array}$ & $\begin{array}{c}\text { Confirmed } \\
\text { by MRM } \\
\text { with } \\
\text { stable } \\
\text { isotope } \\
\text { standards }\end{array}$ \\
\hline $\begin{array}{l}\text { ADSLVESGQFDTAGIQ } \\
\text { EK }\end{array}$ & $\begin{array}{l}\text { alpha- } \\
\text { Spec }\end{array}$ & M9PGV6 & $Q>R$ & & $\sqrt{ }$ & & & $\sqrt{ }$ & & & $\checkmark$ & & \\
\hline LVTTVSTPVFDGR & CG4587 & A8DZ06 & $R>G$ & & $\sqrt{ }$ & & & $\mathrm{V}$ & & & $\mathrm{V}$ & & Yes \\
\hline $\begin{array}{l}\text { IEYHVEHAVDYVQTAT } \\
\text { QDTK }\end{array}$ & Syx1A & Q24547 & $M>V$ & & $\sqrt{ }$ & & & $\checkmark$ & & & $\sqrt{ }$ & & Yes \\
\hline $\begin{array}{l}\text { GVGPAPSANASADSS } \\
\text { SR }\end{array}$ & Atx2 & $\begin{array}{l}\text { Q8SWR8 } \\
-2\end{array}$ & $K>R$ & & V & & $\sqrt{ }$ & & & $\mathrm{V}$ & & & No \\
\hline LVSVLESTLSK & Cadps & $\begin{array}{l}\text { Q9NHE5- } \\
2\end{array}$ & $\mathrm{M}>\mathrm{V}$ & & $\sqrt{ }$ & & $\sqrt{ }$ & & & $\sqrt{ }$ & & & Yes \\
\hline NQMETQVNELK & $\mathrm{cpx}$ & E1JJ33 & $\mathrm{I}>\mathrm{M}$ & & $\sqrt{ }$ & & $\sqrt{ }$ & & & V & & & Yes \\
\hline $\begin{array}{l}\text { YSLDDNIEQNFLEPLH } \\
\text { HMQTK }\end{array}$ & EndoA & B5RIU6 & $K>E$ & & $\sqrt{ }$ & & $\sqrt{ }$ & & & $\sqrt{ }$ & & & Yes \\
\hline $\begin{array}{l}\text { MTVAHMWFDNQIIE } \\
\text { ADTTEDQSGVQCDR }\end{array}$ & Atpalpha & P13607-7 & $Y>C$ & $\sqrt{ }$ & & & $\sqrt{ }$ & & & v & & & \\
\hline YLLQIWPQPQAQHQR & $\begin{array}{l}\text { RhoGAP1 } \\
\text { OOF }\end{array}$ & Q9V9S7 & $Q>R$ & $\checkmark$ & & & & & & $\sqrt{ }$ & & & No \\
\hline AIAGVLTPLNPLWALR & CG1882 & Q5U191 & $\mathrm{R}>\mathrm{G}$ & $\sqrt{ }$ & $\sqrt{ }$ & & V & & & & & & \\
\hline $\begin{array}{l}\text { EDIQANQLVMGEFEV } \\
\text { SDVPGQIIDYVAR }\end{array}$ & bai & Q8SXY6 & $\mathrm{I}>\mathrm{V}$ & & $\sqrt{ }$ & & $\sqrt{ }$ & & & & & & \\
\hline FIYVSEEELLAVAK & CG5862 & Q9VDD1 & $\mathrm{K}>\mathrm{E}$ & & $\sqrt{ }$ & & $\sqrt{ }$ & & & & & & \\
\hline GALSSAGYHLNNR & CalpB & M9NE73 & $\mathrm{N}>\mathrm{S}$ & & $\sqrt{ }$ & & $\sqrt{ }$ & & & & & & \\
\hline LHAGDDEEADDPIR & Calx & Q9VDG5 & $Q>R$ & & $\sqrt{ }$ & & $\sqrt{ }$ & & & & & & \\
\hline TAGPLPGGR & CG10508 & M9PFU5 & $S>G$ & & $\sqrt{ }$ & & $\sqrt{ }$ & & & & & & \\
\hline $\begin{array}{l}\text { AIHALAAGASSSAEQD } \\
\text { GAYNPWPHFR }\end{array}$ & CG13630 & Q9VC48 & $\mathrm{N}>\mathrm{S}$ & & & $\mathrm{V}$ & & & $\checkmark$ & & & & \\
\hline DLVATVLDMK & eag & QOKHS8 & $I>V$ & & V & & $\checkmark$ & & & & & & \\
\hline
\end{tabular}




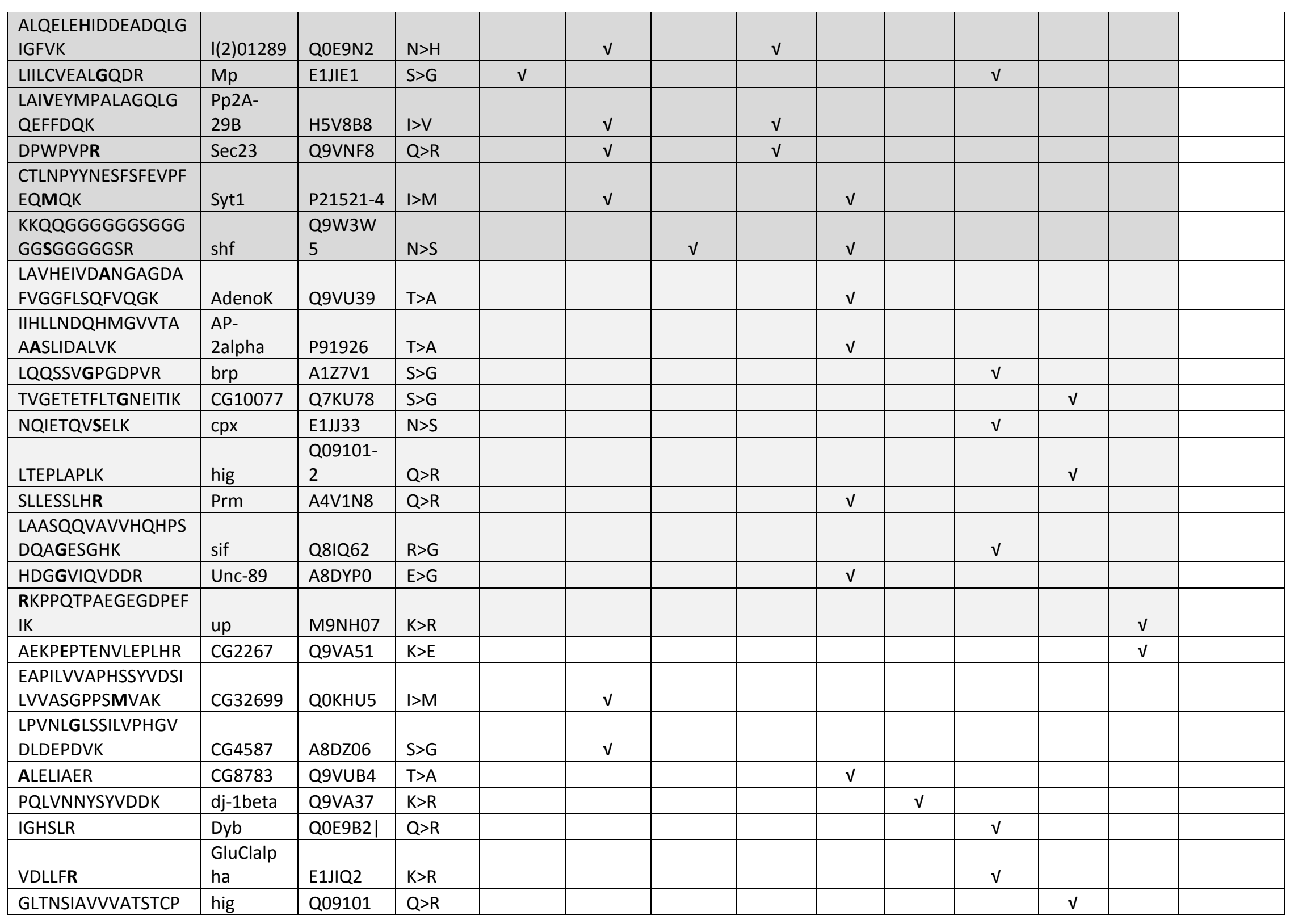




\begin{tabular}{|c|c|c|c|c|c|c|c|c|c|c|c|c|c|}
\hline $\mathbf{R}$ & & & & & & & & & & & & & \\
\hline $\begin{array}{l}\text { MDITWFPFDDQHCE } \\
\text { MK }\end{array}$ & $\begin{array}{l}\text { nAChRal } \\
\text { pha6 }\end{array}$ & Q8IPE2 & $\mathrm{I}>\mathrm{M}$ & & $\sqrt{ }$ & & & & & & & & \\
\hline $\begin{array}{l}\text { KTAGGSLEMFMTEDQ } \\
\mathrm{K}\end{array}$ & para & M9MS79 & $K>T$ & & & & & & & $\sqrt{ }$ & & & \\
\hline LSFRASGGSNGR & Pde1c & B7YZV2 & $S>R$ & & & & & & & $\sqrt{ }$ & & & \\
\hline VEIELDSVR & Prm & A4V1N8 & $Q>R$ & & & & & $\mathrm{~V}$ & & & & & \\
\hline GFQPGPSVVGR & pyd & A8JQV8 & $S>G$ & & $\sqrt{ }$ & & & & & & & & \\
\hline NTCVFGGAPR & Rm62 & P19109-2 & $K>R$ & & & & & & & & $\mathrm{~V}$ & & \\
\hline REGTTSGDKR & rnh1 & A1Z768 & $K>E$ & & & $\mathrm{~V}$ & & & & & & & \\
\hline VTKGGAGATGAAGK & RpL34b & Q9VHE5 & $K>T$ & & & & & & & V & & & \\
\hline SSNQAMSLAMLR & Sh & P08510-3 & $\mathrm{I}>\mathrm{M}$ & & $\sqrt{ }$ & & & & & & & & \\
\hline MDPMIYMFPR & shakB & P33085 & $\mathrm{I}>\mathrm{M}$ & & $\sqrt{ }$ & & & & & & & & \\
\hline $\begin{array}{l}\text { MALTSYDQIPSELAPY } \\
\text { AFVEFTMPATQVSHA } \\
\text { TVR }\end{array}$ & $\operatorname{stn} B$ & X2JGF5 & $\mathrm{T}>\mathrm{A}$ & & & & & $\sqrt{ }$ & & & & & \\
\hline EGLLQR & Syn & E2QCY9 & $S>G$ & & & & & & & $\sqrt{ }$ & & & \\
\hline QQLGSILMSAPR & Tfb4 & Q9VPX4 & $N>S$ & & & & & & & & & $\mathrm{~V}$ & \\
\hline DHCIAMVQCR & VhaSFD & Q9V3J1 & $\mathrm{K}>\mathrm{R}$ & & & & & $\mathrm{V}$ & & & & & \\
\hline $\begin{array}{l}\text { DHCIAMVQCTVLKQL } \\
\text { SILEQR }\end{array}$ & VhaSFD & $\begin{array}{l}\text { Q9V3J1- } \\
3\end{array}$ & $K>T$ & & & & & & & $\sqrt{ }$ & & & \\
\hline EQLATLMDTLR & zip & $\begin{array}{l}\text { Q99323- } \\
1\end{array}$ & $K>T$ & & & & $\checkmark$ & & & & & & \\
\hline AHSDLTGVK & Calx & Q9VDG5 & $E>G$ & & & & $\mathrm{~V}$ & & & & & & \\
\hline SHHSSSRGKYER & CG31211 & Q86B99 & $S>G$ & $\mathrm{~V}$ & & & & & & & & & \\
\hline $\begin{array}{l}\text { QDSPSQTPTIVVKDSS } \\
\text { NAKLNHTK }\end{array}$ & Cp190 & Q24478 & $\mathrm{I}>\mathrm{V}$ & & & $\checkmark$ & & & & & & & \\
\hline LKNQMETQVNELK & $\mathrm{cpx}$ & E1JJ33 & $\mathrm{I}>\mathrm{M}$ & & & & $\mathrm{V}$ & & & & & & \\
\hline APNPLVYDPK & Сyp6a8 & Q27593 & $\mathrm{T}>\mathrm{A}$ & & & & & & $\sqrt{ }$ & & & & \\
\hline QQQQLQHSQQLPR & $\ln R$ & P09208 & $\mathrm{N}>\mathrm{S}$ & & & & & & $\mathrm{V}$ & & & & \\
\hline FLAGEADKK & $\mathrm{Tm} 1$ & P49455-2 & $E>G$ & & & & $\mathrm{~V}$ & & & & & & \\
\hline $\begin{array}{l}\text { ASTLSSSTSPSMSSSSA } \\
\text { SNHPGHSQSQR }\end{array}$ & $\begin{array}{l}\text { Rab3- } \\
\text { GEF }\end{array}$ & Q9VXY2 & $Q>R$ & & & & 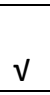 & & & & & & \\
\hline IMTFVGGPCSR & $\operatorname{Sec} 23$ & Q9VNF8 & $Q>R$ & & & & $\mathrm{~V}$ & & & & & & \\
\hline $\begin{array}{l}\text { RQTDGQWDLNGYHL } \\
\text { VTLGDR }\end{array}$ & syd & $\begin{array}{l}\text { Q9GQF1- } \\
2\end{array}$ & $S>G$ & & $\sqrt{ }$ & & & & & & & & \\
\hline
\end{tabular}




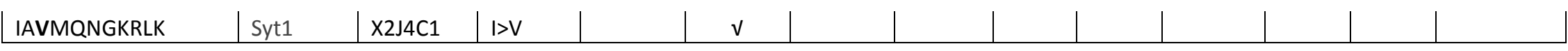

47 
Table 2. Validation of A-to-I editing sites at the level of genomic DNA, RNA and proteome. Sanger sequencing of amplified DNA was performed to confirm that the substitutions have happened post-transcriptionally. RNA editing events in the transcriptome level were confirmed using ICE method ${ }^{3}$. Edited protein sequences were validated using Miltiple Reaction Monitoring (MRM) using stable isotope labeled standards.

\begin{tabular}{|c|c|c|c|c|c|c|}
\hline \multirow[t]{2}{*}{ Gene name } & \multirow[t]{2}{*}{$\begin{array}{l}\text { Putative } \\
\text { genomic } \\
\text { variant }\end{array}$} & \multirow{2}{*}{$\begin{array}{c}\text { Sequence } \\
\text { of } \\
\text { amplified } \\
\text { DNA }\end{array}$} & \multicolumn{2}{|c|}{$\begin{array}{c}\text { Sequence of } \\
\text { amplified } \\
\text { cDNA }\end{array}$} & \multirow{2}{*}{$\begin{array}{c}\text { RNA } \\
\text { editing } \\
\text { confirmed } \\
\text { by ICE-seq }\end{array}$} & \multirow{2}{*}{$\begin{array}{c}\text { Amino } \\
\text { acid } \\
\text { change } \\
\text { confirmed } \\
\text { by MRM }\end{array}$} \\
\hline & & & CE- & $\mathbf{C E}+$ & & \\
\hline Alpha-Spec & A/G:Q1700R & $\mathrm{T}$ & $\mathrm{A}$ & A & No & $\mathrm{N} / \mathrm{A}$ \\
\hline Atpalpha & A/G:Y390C & $\mathrm{T}$ & $\mathrm{A} / \mathrm{G}$ & A & Yes & $\mathrm{N} / \mathrm{A}$ \\
\hline Atx2 & A/G:K398R & $\mathrm{T}$ & $\mathrm{A}$ & $\mathrm{A}$ & No & No \\
\hline Cadps & A/G:M1234V & $\mathrm{T}$ & $\mathrm{A} / \mathrm{G}$ & $\mathrm{A}$ & Yes & Yes \\
\hline$C G 4587$ & A/G:R489G & $\mathrm{T}$ & $\mathrm{A}$ & $\mathrm{A}$ & No & Yes \\
\hline$C p x$ & A/G:I125M & $\mathrm{T}$ & $\mathrm{A} / \mathrm{G}$ & $\begin{array}{c}\text { No } \\
\text { product }\end{array}$ & Yes & Yes \\
\hline EndoA & A/G:K137E & $\mathrm{T}$ & A & $\mathrm{A}$ & No & Yes \\
\hline RhoGAP1OoF & A/G:Q1142R & $\mathrm{T}$ & $\mathrm{A}$ & $\mathrm{A}$ & No & No \\
\hline Syx1A & A/G:M244V & $\mathrm{T}$ & $\mathrm{A} / \mathrm{G}$ & A & Yes & Yes \\
\hline
\end{tabular}


Table 3. Quantitation of selected edited sites and their genomic variants in the brain hydrolysate of the fruit fly by Multiple Reaction Monitoring (MRM) with stable isotope labelled standards.

\begin{tabular}{|c|c|c|c|c|c|c|c|}
\hline Gene name & Edited site & \multicolumn{2}{|c|}{ Tryptic peptide sequence for MRM study } & $\begin{array}{l}\text { Result of } \\
\text { ICE seq }\end{array}$ & $\begin{array}{l}\text { Abundance, } \mathrm{nmol} / \mathrm{g} \text { total } \\
\text { protein (av. } \pm \text { st.d.) }\end{array}$ & $\mathrm{CV}, \%$ & $\begin{array}{l}\text { Ratio o } \\
\text { edited }\end{array}$ \\
\hline \multirow{2}{*}{$S y x 1 A$} & \multirow{2}{*}{$\mathrm{M} 244 \mathrm{~V}$} & Genomic & IEYHVEHAMDYVQTATQDTK & \multirow{2}{*}{ Yes } & $10.1 \pm 1.4$ & 13.7 & \multirow{2}{*}{4.6} \\
\hline & & Edited & IEYHVEHAVDYVQTATQDTK & & $0.5 \pm 0.04$ & $7 \cdot 7$ & \\
\hline \multirow{2}{*}{$c p x$} & \multirow{2}{*}{$\mathrm{I} 125 \mathrm{M}$} & Genomic & NQIETQVNELK & \multirow{2}{*}{ Yes } & $33.4 \pm 1.6$ & 4.9 & \multirow{2}{*}{$25 \cdot 9$} \\
\hline & & Edited & NQMETQVNELK & & $11.1 \pm 0.5$ & 4.1 & \\
\hline EndoA & $\mathrm{K} 137 \mathrm{E}$ & Edited & YSLDDNIEQNFLEPLHHMQTK & No & $44.1 \pm 1.4$ & 3.1 & 73.8 \\
\hline \multirow{2}{*}{$C G 4587$} & \multirow{2}{*}{ R489G } & Genomic & LVTTVSTPVFDR & \multirow{2}{*}{ No } & $2.8 \pm 0.2$ & 6.7 & \multirow{2}{*}{62.2} \\
\hline & & Edited & LVTTVSTPVFDGR & & $4.5 \pm 0.1$ & 1.5 & \\
\hline Cadps & M1234V & Genomic & LMSVLESTLSK & Yes & $2.3 \pm 0.1$ & $5 \cdot 5$ & 36.7 \\
\hline \multirow{2}{*}{ RhoGAP1OoF } & \multirow{2}{*}{ Q1142R } & Genomic & YLLQIWPQPQAQHR & \multirow{2}{*}{ No } & \multirow{2}{*}{\multicolumn{2}{|c|}{ Not detected }} & \\
\hline & & Edited & YLLQIWPQPQAQHQR & & & & \\
\hline
\end{tabular}




\section{Graphical abstract, for TOC only.}
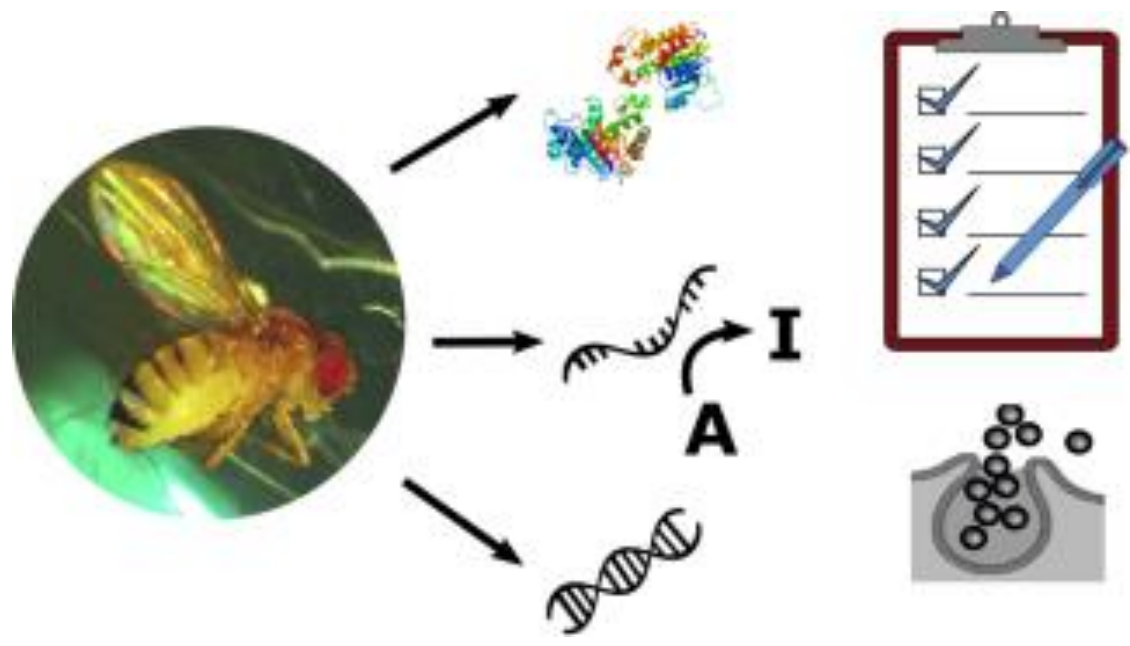


\section{Proteome Xchange}

Xing et al.

transcriptomic data from

St Laurent et al., 2013 and FlyBase

[Ramaswami et al., 2014]

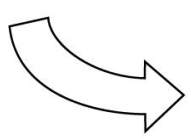
(whole body proteome)

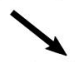

Aradska et al. (whole head proteome)

customized proteomic databases
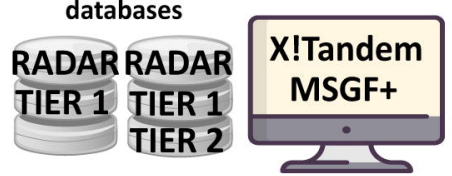

(brain proteome)

$$
\downarrow
$$

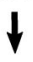

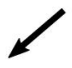

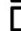

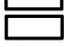

shotgun analysis
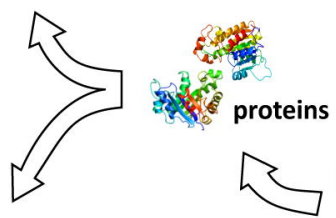

\section{LC-MS/MS}

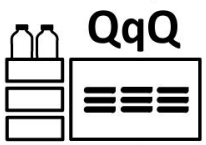

MRM analysis
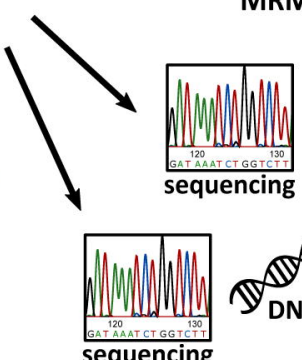
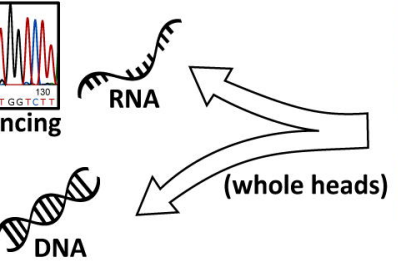

sequencing

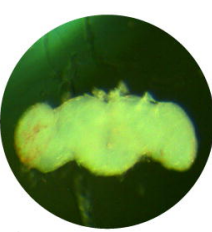

brain dissection
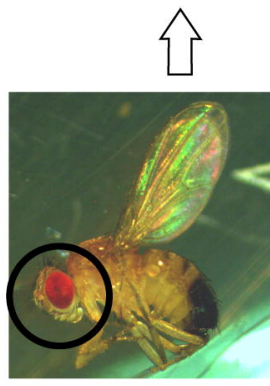

D. melanogaster Canton-S culture 


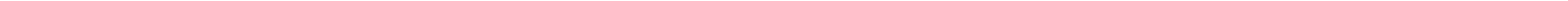


A
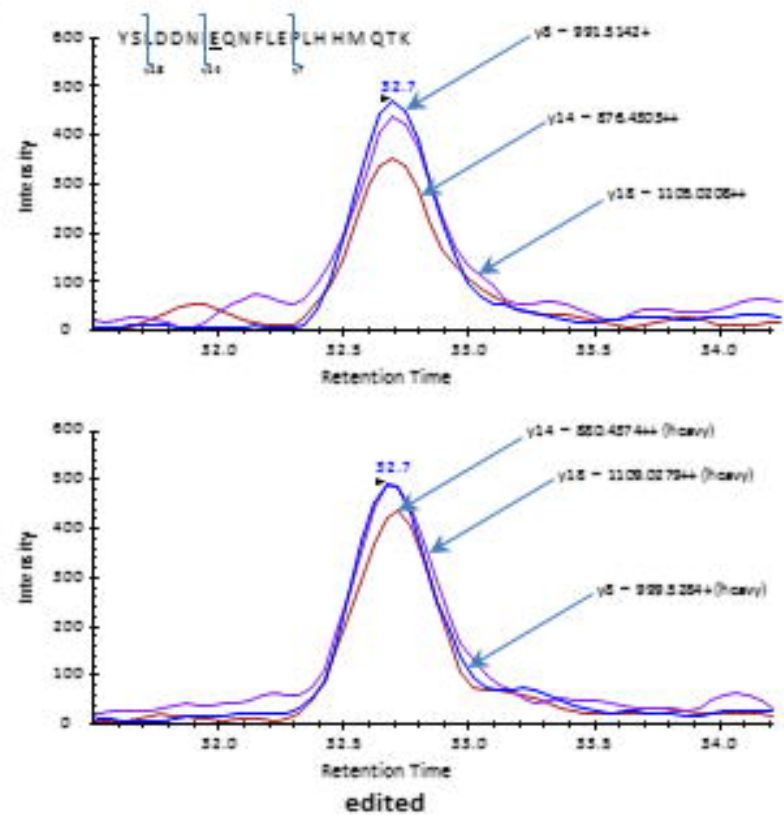

B
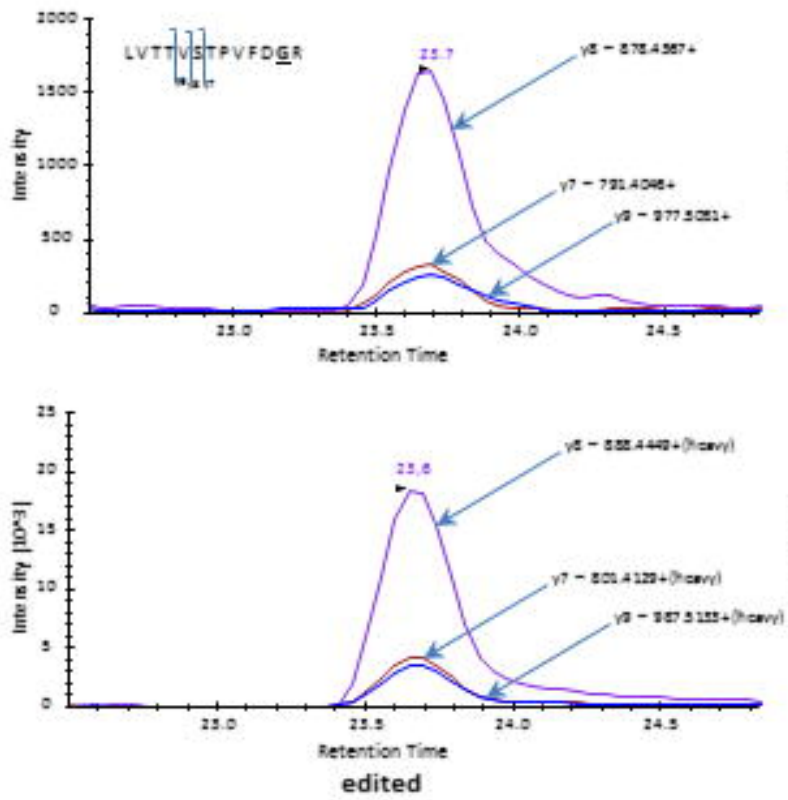

\section{EndoA}
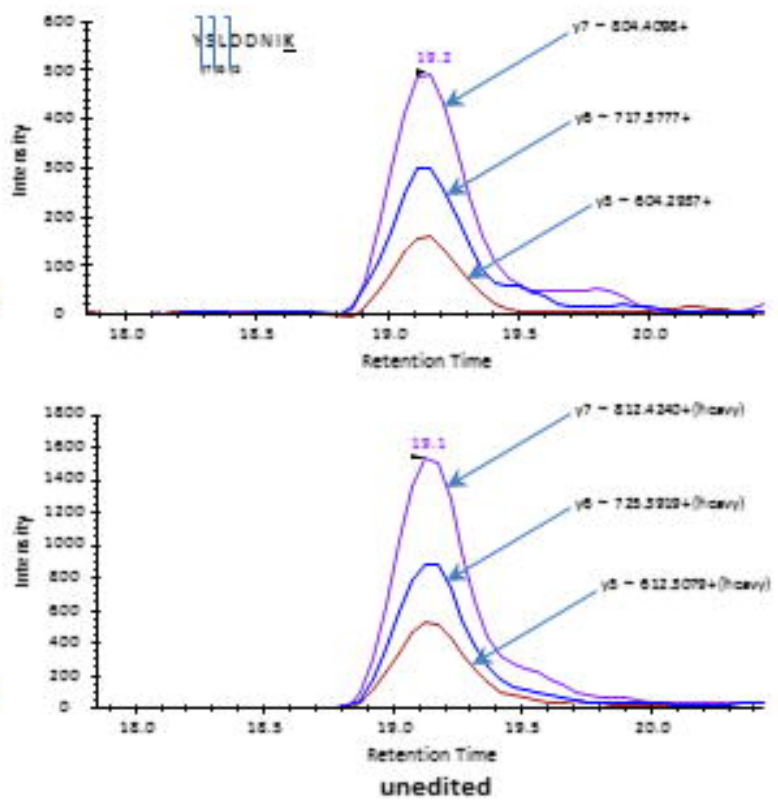

\section{CG4587}
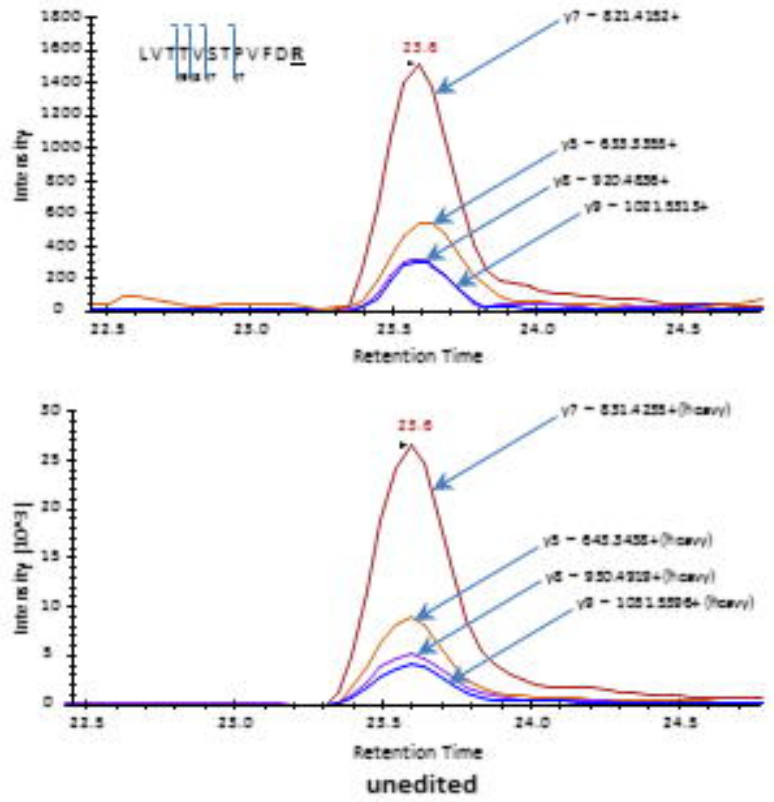


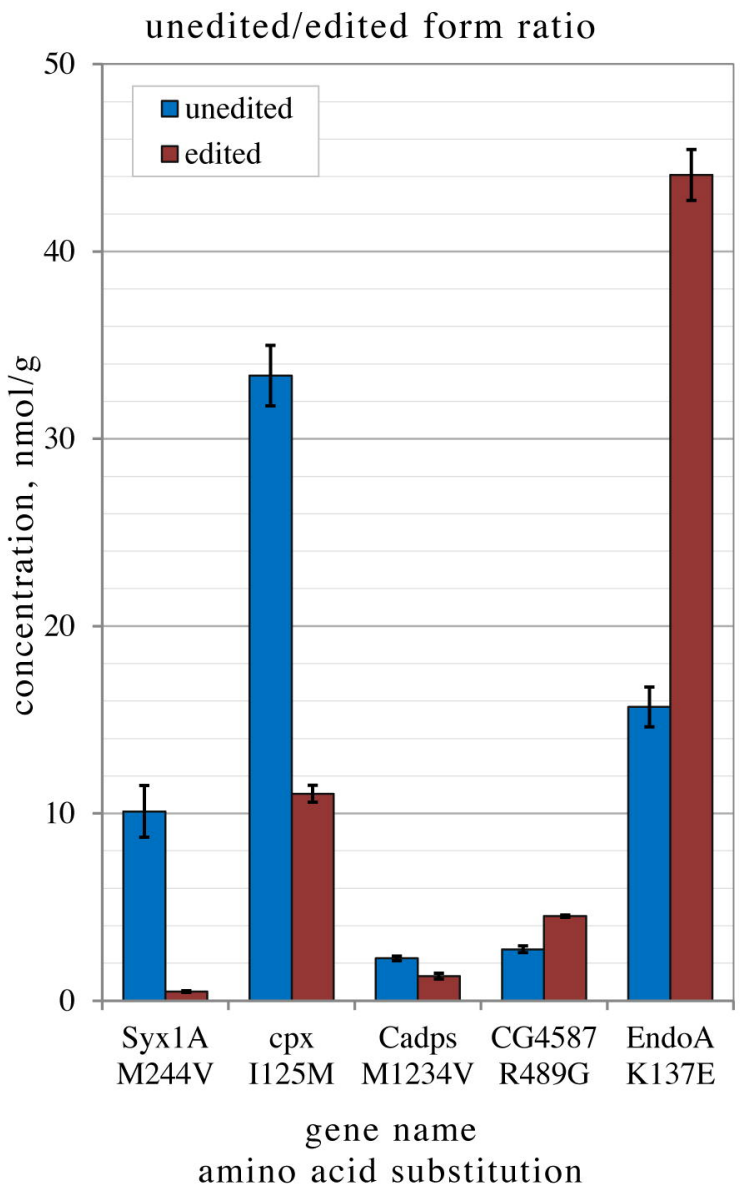




\section{Endophilin A}

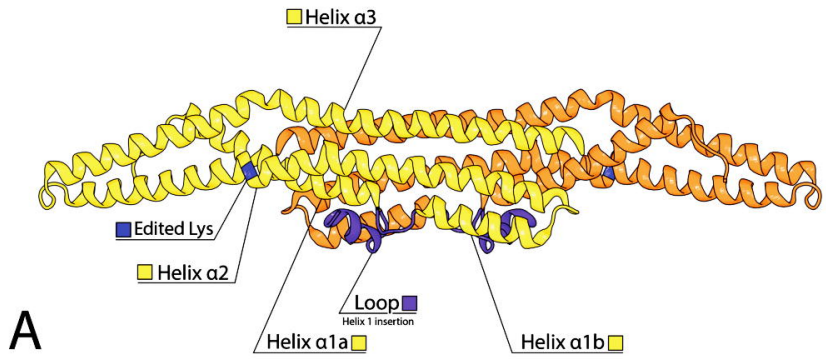

$\mathrm{E}$

Drosophila melanogaster YYSLDDNI KQNFLEPLHHMOTKDLKEVMHHRKKLQGRRLDFD

Gallus gallus DSLDMEVKQNFIDPLQN LLHDKDLREI QHHLKKMEGRRLDFD 7 EndoA 1

Gallus gallus IDSLD I EVKQNFIDPLQN LCDKDLKEI QHHLKKL EGRRLDFD

Gallus gallus DSLD I NVKQNFIDPLQL LQDKDLKEI GHHLKKL EGRRLDYD Mus musculus DSLDMEVKQNFIDPLQN LHDKDLRE I QHHLKKL EGRRLDFD Mus musculus DSLD I EVKQNFIDPLQN_LCDKDLKEI QHHLKK L EGRRLDFD Mus musculus DSLD I NVKQT FIDPLQL LODKDLKEI GHHLRK L EGRRLDYD Homo sapiens 'DSLD I EVKQNFIDPLQN LL HDKDLREI QHHLKKL EGRRLDFD Homo sapiens DSLD I EVKQNFIDPLQN LCE KDLKEI QHHLKKL EGRRLDFD Homo sapiens 'DSLD INVKQTFIDPLQL LQDKDLKE I GHHLKK EGRRLDY'

B

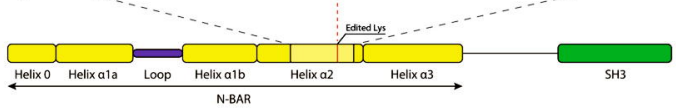

